\title{
Evaluating the diurnal cycle in cloud top temperature from SEVIRI
}

\author{
Sarah Taylor ${ }^{1}$, Philip Stier ${ }^{1}$, Bethan White ${ }^{1}$, Stephan Finkensieper ${ }^{2}$, and Martin Stengel ${ }^{2}$ \\ ${ }^{1}$ Atmospheric, Oceanic and Planetary Physics, Department of Physics, University of Oxford, UK \\ ${ }^{2}$ Deutscher Wetterdienst (DWD), Offenbach, Germany
}

Correspondence to: Sarah Taylor (sarah.taylor@ physics.ox.ac.uk)

Received: 2 October 2016 - Discussion started: 31 October 2016

Revised: 14 March 2017 - Accepted: 18 April 2017 - Published: 14 June 2017

\begin{abstract}
The variability of convective cloud spans a wide range of temporal and spatial scales and is of fundamental importance for global weather and climate systems. Datasets from geostationary satellite instruments such as the Spinning Enhanced Visible and Infrared Imager (SEVIRI) provide high-time-resolution observations across a large area. In this study we use data from SEVIRI to quantify the diurnal cycle of cloud top temperature within the instrument's field of view and discuss these results in relation to retrieval biases.

We evaluate SEVIRI cloud top temperatures from the new CLAAS-2 (CLoud property dAtAset using SEVIRI, Edition 2) dataset against Cloud-Aerosol Lidar with Orthogonal Polarization (CALIOP) data. Results show a mean bias of $+0.44 \mathrm{~K}$ with a standard deviation of $11.7 \mathrm{~K}$, which is in agreement with previous validation studies. Analysis of the spatio-temporal distribution of these errors shows that absolute retrieval biases vary from less than $5 \mathrm{~K}$ over the southeast Atlantic Ocean up to $30 \mathrm{~K}$ over central Africa at night. Night- and daytime retrieval biases can also differ by up to $30 \mathrm{~K}$ in some areas, potentially contributing to biases in the estimated amplitude of the diurnal cycle. This illustrates the importance of considering spatial and diurnal variations in retrieval errors when using the CLAAS-2 dataset.

Keeping these biases in mind, we quantify the seasonal, diurnal, and spatial variation of cloud top temperature across SEVIRI's field of view using the CLAAS-2 dataset. By comparing the mean diurnal cycle of cloud top temperature with the retrieval bias, we find that diurnal variations in the retrieval bias can be small but are often of the same order of magnitude as the amplitude of the observed diurnal cycle, indicating that in some regions the diurnal cycle apparent in the observations may be significantly impacted by diurnal variability in the accuracy of the retrieval.
\end{abstract}

We show that the CLAAS-2 dataset can measure the diurnal cycle of cloud tops accurately in regions of stratiform cloud such as the southeast Atlantic Ocean and Europe, where cloud top temperature retrieval biases are small and exhibit limited spatial and temporal variability. Quantifying the diurnal cycle over the tropics and regions of desert is more difficult, as retrieval biases are larger and display significant diurnal variability. CLAAS-2 cloud top temperature data are found to be of limited skill in measuring the diurnal cycle accurately over desert regions. In tropical regions such as central Africa, the diurnal cycle can be described by the CLAAS-2 data to some extent, although retrieval biases appear to reduce the amplitude of the real diurnal cycle of cloud top temperatures.

This is the first study to relate the diurnal variations in SEVIRI retrieval bias to observed diurnal cycles in cloud top temperature. Our results may be of interest to those in the observation and modelling communities when using cloud top properties data from SEVIRI, particularly for studies considering the diurnal cycle of convection.

\section{Introduction}

The diurnal and seasonal cycles of cloud top temperature (CTT), driven by changes in solar insolation, are among the strongest and most fundamental modes of variation in the global weather and climate systems. These cycles play important roles in the hydrological cycle; the global energy budget; and the transport of heat, moisture, and momentum throughout the troposphere. While areas of convective cloud are associated with the strongest diurnal and seasonal cycles in CTT, areas of non-convective cloud also have observable diurnal and seasonal cycles (Yang and Slingo, 2001). 
A large number of observational studies using data from rain gauges (Wallace, 1975; Gray and Jacobsen, 1977), surface weather reports (Dai, 2001), and both polar-orbiting (Nesbitt and Zipser, 2003; Yang et al., 2008; Stratton and Stirling, 2012) and geostationary (Meisner and Arkin, 1987; Janowiak et al., 1994; Chen and Houze, 1997; Yang and Slingo, 2001; Schröder et al., 2009) satellites have attempted to quantify the diurnal cycle of cloud over land. These studies found an early-afternoon maximum in precipitation, followed by a minimum in cloud top temperature approximately $3 \mathrm{~h}$ later. The two features are thought to correspond to the beginning and end of the mature stage of convection (Schröder et al., 2009).

However, these large-scale convective features, driven by insolation, display regional and seasonal variations (Yang and Slingo, 2001; Schröder et al., 2009) and can be overridden by other factors such as orography (Yang and Slingo, 2001; Nesbitt and Zipser, 2003; Vondou et al., 2010), landsea breezes (Chen and Houze, 1997; Yang and Slingo, 2001; Halladay et al., 2012) and the organization of convection (Nesbitt and Zipser, 2003).

The amplitude of the diurnal cycle of CTT is smaller over the ocean than over land (Harrison et al., 1988), due to the ocean's higher heat capacity and because ocean mixing distributes incoming solar radiation away from the surface. Over large areas of the ocean there is a small diurnal cycle in CTT, caused by stratiform cloud (Yang and Slingo, 2001; Wood, 2002; Duynkerke et al., 2004). During the night, longwave radiative cooling at the cloud top drives turbulent mixing, creating a deeper cloud layer. In the daytime, solar heating of the cloud top causes the cloud layer to become stably stratified, cutting off the transport of heat and moisture from the surface, creating a thinner cloud layer (Duynkerke et al., 2004).

Most studies show a substantial pre-dawn peak in convective cloud over the oceans (Janowiak et al., 1994; Yang and Slingo, 2001; Nesbitt and Zipser, 2003; Bain et al., 2010; Stengel et al., 2014). The mechanisms responsible for this overnight peak in convective cloud remain uncertain (Bain et al., 2010) but are thought to be related to atmospheric instability caused by night-time radiative cooling (Randall et al., 1991) and to the presence of a larger number of mesoscale convective systems (MCSs) during the night (Chen and Houze, 1997; Nesbitt and Zipser, 2003).

General circulation models (GCMs) and numerical weather prediction (NWP) models struggle to realistically simulate spatial and temporal variability of cloud, due to the complexity of the processes involved, from large-scale atmospheric circulations and boundary layer processes to convection and cloud microphysics. A particular concern is that models fail to capture the observed diurnal cycle of convective cloud (Yang and Slingo, 2001; Guichard et al., 2004; Grabowski et al., 2006; Stratton and Stirling, 2012).

This is generally the result of convection initiating shortly after sunrise, which develops too rapidly, quickly reaching the tropopause and producing precipitation (Guichard et al., 2004; Stratton and Stirling, 2012). Studies by Guichard et al. (2004), Grabowski et al. (2006), and Sato et al. (2009) show that in some cases cloud-resolving models (CRMs), which explicitly resolve convection, are capable of correctly predicting the amplitude and phase of the diurnal cycle in convection. Over land, this accuracy is strongly dependent on horizontal resolution, requiring grid lengths of around $1 \mathrm{~km}$ (Guichard et al., 2004) or $500 \mathrm{~m}$ (Grabowski et al., 2006). Over the ocean, horizontal resolution appears to be less important, which is likely due to differences in predominant cloud types and lifecycles (Sato et al., 2009). However, Pearson et al. $(2010,2014)$ show that the mechanisms used to represent convection and the scale at which parameterization schemes are employed, rather than spatial resolution, are key to improving the representation of the diurnal evolution and growth of tropical convective systems.

Observations can both improve our theoretical understanding and provide a useful test of a model's ability to capture the various scales of variation of cloud. Regions of stratiform cloud cover large areas and can persist for days. However, spatial scales of convection range from thousands of kilometres for MCSs to a few kilometres for individual convective plumes, while timescales of convective variability range from minutes through to seasons.

While low-Earth-orbit satellites can provide observations at high spatial resolution, their temporal sampling is limited. Polar-orbiting satellites in Sun-synchronous orbit, such as those in the A-Train constellation of satellites, observe any given point (except polar regions, which are observed more often) no more than twice per day and always at the same local solar time. Other low-Earth-orbit satellites, such as the Tropical Rainfall Measuring Mission (TRMM), are able to sample a given point at varying local solar times, thereby providing statistical diurnal cycle observations. Individual lowEarth-orbit satellites are therefore unable to observe the temporal evolution of cloud, particularly rapidly evolving convective cloud.

In comparison, while the spatial resolution of geostationary satellites is limited, they provide high-temporalresolution observations over a large area. The Spinning Enhanced Visible and Infrared Imager (SEVIRI) instrument on board the geostationary Meteosat Second Generation (MSG) satellites has a spatial resolution of $3 \mathrm{~km}$ at the satellite nadir and a temporal resolution of $15 \mathrm{~min}$, with a record of observations reaching back to 2004. Its field of view, hereafter referred to as the SEVIRI "disc", covers the entire continents of Africa and Europe, as well as parts of the Middle East, South America, and both the Atlantic and Indian oceans. The continuous nature of SEVIRI's observations makes them ideal for investigating the temporal and spatial variability of cloud across a large area and period of time.

It should be noted that the radiances observed by a passive imager such as SEVIRI are weighted averages of the vertical temperature profile of the atmosphere. The contri- 
bution of each layer of the atmosphere to the observed radiance can be described for each channel by a weighting function, which varies according to the viewing angle and atmospheric state. The cloud top height $(\mathrm{CTH})$ inferred from these radiances will therefore be lower and warmer than the physical CTH, which can be measured by active lidar instruments such as the Cloud-Aerosol Lidar with Orthogonal Polarization (CALIOP) even for optically thick cloud (Sherwood et al., 2004). SEVIRI is therefore expected to underestimate CTH and overestimate cloud top pressure (CTP) and CTT relative to CALIOP. This is due to differences in the properties observed by the two instruments, rather than an error in the SEVIRI retrieval.

Although it is often assumed that optically thick clouds have sharp boundaries and can be expected to radiate as black bodies (Sherwood et al., 2004; Stubenrauch et al., 2013), the radiometric height of a cloud may be several kilometres below physical cloud top height depending on its extinction profile at the cloud top and its vertical size (Stubenrauch et al., 2013). In particular, glaciated clouds tend to have poorly defined edges, even when convectively active (Sherwood et al., 2004), and so optical depths increase slowly with distance from the cloud top (Stubenrauch et al., 2013).

Sherwood et al. (2004) found that radiometric cloud tops retrieved from the Geostationary Operational Environmental Satellite 8 (GOES-8) were on average $1 \mathrm{~km}$ below or 5$7 \mathrm{~K}$ above the visible cloud tops observed by NASA's Cloud Physics Lidar (CPL). This bias increased to $2 \mathrm{~km}$ for the highest cloud tops and was not found to vary with cloud albedo. Other studies (Heymsfield et al., 1991; Minnis et al., 2008; Stubenrauch et al., 2010, 2013) show similar biases of between 0.5 and $3 \mathrm{~km}$ for high clouds in the tropics.

An additional cause of differences between the cloud properties observed by CALIOP and SEVIRI is the occurrence of optically thin clouds or cloud layers. Using $532 \mathrm{~nm}$ measurements, CALIOP is capable of detecting cloud layers with optical depths of 0.01 (Vaughan et al., 2009; NASA, 2013), which SEVIRI is not sensitive enough to detect (Heidinger and Pavolonis, 2009; Stubenrauch et al., 2010; SAFNWC/MSG, 2012). The impact of these clouds on passively measured radiation is small and thus not properly detected by passive imager sensors (Heidinger and Pavolonis, 2009; Stubenrauch et al., 2010; SAFNWC/MSG, 2012). This is a particular issue in the case of pixels containing semitransparent cloud types, which have low optical depths, as it is difficult to fully account for contributions from surface radiation or low cloud layers underneath (Smith and Platt, 1978).

In this study we evaluate SEVIRI CTT retrievals dataset against data from CALIOP in order to consider spatial and diurnal variability in retrieval biases and investigate the seasonal and diurnal cycles of CTT across the entire SEVIRI disc. This is the first study to relate the diurnal variations in retrieval bias to observed diurnal cycles in CTT for SEVIRI cloud top properties as contained in the 12-year-spanning
SEVIRI dataset. The SEVIRI dataset is introduced in Sect. 2. Based on this dataset, spatial and seasonal patterns in CTT are examined in Sect. 3.1. In Sect. 3.2 the SEVIRI cloud top temperature data are compared to CALIOP measurements, extending on existing validation analyses in order to consider the implications of spatial and diurnal variations in retrieval bias for the SEVIRI-based diurnal cycles of CTT. In Sect. 3.3, the diurnal variability of cloud top temperature is quantified across the SEVIRI disc. Conclusions are presented in Sect. 4.

\section{Data}

The analysis presented here uses data from the MSG series of geostationary satellites. Operational MSG satellites are centred near $0^{\circ}$ longitude (although gaps in coverage are occasionally filled using data from older versions of the satellite, located near $3.5^{\circ} \mathrm{E}$; Meirink, 2013). The SEVIRI imager is the main payload on the MSG series of satellites. It has 12 spectral channels in the visible, near-infrared, and infrared; a temporal resolution of $15 \mathrm{~min}$ ( $5 \mathrm{~min}$ in rapid scan mode, covering a limited area); and a spatial resolution ranging from $3 \mathrm{~km}$ at satellite nadir $(1 \mathrm{~km}$ in its high-resolution visible channel) to $11 \mathrm{~km}$ at the edge of its field of view.

The European Organisation for the Exploitation of Meteorological Satellites (EUMETSAT)'s Satellite Application Facility on Climate Monitoring (CMSAF) has produced an updated 12-year dataset of cloud top properties based on SEVIRI measurements, named the CLoud property dAtAset using SEVIRI, Edition 2 (CLAAS-2; Finkensieper et al., 2016; Benas et al., 2016). CLAAS-2 contains the only retrieval of cloud top properties currently available at full SEVIRI spatial and temporal resolution and over a period of several years. The specific dataset used in this study is the instantaneous cloud top parameters product (CTX version 002; Benas et al., 2016). The dataset is available for the period 2004-2015 and retrieved at full SEVIRI spatial and temporal resolution.

The retrieval algorithm applied to produce the CLAAS2 dataset was developed in the framework of the EUMETSAT Satellite Application Facility on Nowcasting (NWC SAF). The full algorithms (NWC SAF/MSGv2012) are documented in Derrien (2013). A short summary of the cloud detection and the cloud top pressure retrieval is presented here.

Cloud detection is based on a multi-spectral threshold method, applying a variety of threshold tests in different channels, in order to obtain a pixel-resolution cloud mask. These tests vary according to conditions such as solar illumination (day, night, and twilight), satellite angle, and surface type (land, ocean, and coast). During the daytime SEVIRI visible-channel information is available and used. For all pixels identified as cloudy the CTP is derived.

The cloud top pressure retrieval is performed for all cloudy pixels, excluding pixels which contain broken cloud conditions as identified by an intermediate cloud typing procedure. 
This typing procedure further determines whether the clouds are semi-transparent or optically thick, triggering different approaches for the CTP retrieval. It is assumed that the detection of these intermediate cloud types is more accurate under daytime conditions, due to the availability of visiblechannel information. This may subsequently result in more accurate CTP retrievals during the daytime, as found later in this paper.

For high, semi-transparent clouds an $\mathrm{H}_{2} \mathrm{O}-\mathrm{IRW}$ (infrared window) intercept method (Schmetz et al., 1993) is attempted. If this is not successful, the CTP is determined by a radiance rationing method (Menzel et al., 1983). For all other clouds, the $10.8 \mu \mathrm{m}$ brightness temperature is simulated using RTTOV and ERA-Interim (Dee et al., 2011) data while modulating the CTP of the cloud. This allows the CTP for which the simulated brightness temperatures best fits that observed to be identified.

Retrieved CTP is used to infer cloud top temperature using ERA-Interim profiles by selecting the temperature at the same level at which the cloud top pressure is located in the pressure profile. It can be assumed that different NWP models would lead to different CTP retrievals and thus to different cloud top temperatures. For both the radiative transfer simulation and the CTP-to-CTT conversion, 3-hourly ERAInterim data on a $0.5^{\circ}$ grid are utilized. A linear temporal interpolation between the previous and subsequent forecast is performed to represent best the meteorological conditions at the observation time. The vertical resolution of the ERAInterim data used is provided in pressure levels at 1000, 950, 925, 900, 850, 700, 500, 400, 300, 250, 200, 150, 100, 70, 50, 30 , and $10 \mathrm{hPa}$. The discrete vertical resolution will therefore introduce some uncertainty in the retrieval results of cloud top pressure as well as in the conversion from CTP to CTT.

Benas et al. (2016) compare the CLAAS-2 CTT data to measurements from the CALIOP instrument between 2006 and 2015. The comparison is made for the CALIOP cloud layer at which the vertically integrated cloud optical depth (COD) is at least 0.2 . For this setting they find a mean bias of $2.1 \mathrm{~K}$ and a bias-corrected root mean squared error (RMSE) of $16.3 \mathrm{~K}$. Bias and RMSE amount to 11.4 and $22.1 \mathrm{~K}$ when no COD thresholds are applied.

In this study we use CLAAS-2 monthly mean diurnal cycle (MMDC) CTT products, provided at a spatial resolution of $0.25^{\circ}$ and a temporal resolution of $1 \mathrm{~h}$, to quantify the diurnal cycle of CTT across the SEVIRI disc. We also validate instantaneous CTT retrievals (as produced by the NWC SAF/MSG algorithm and included in the CLAAS-2 dataset) against CALIOP, in order to investigate the implications of both the spatial and diurnal variability in the retrieval bias for the accurate quantification of diurnal cycles in cloud top temperature.

All SEVIRI data used in this study are drawn from the CLAAS-2 cloud top temperature dataset, retrieved from SEVIRI observations using the NWC SAF/MSGv2012 algo-
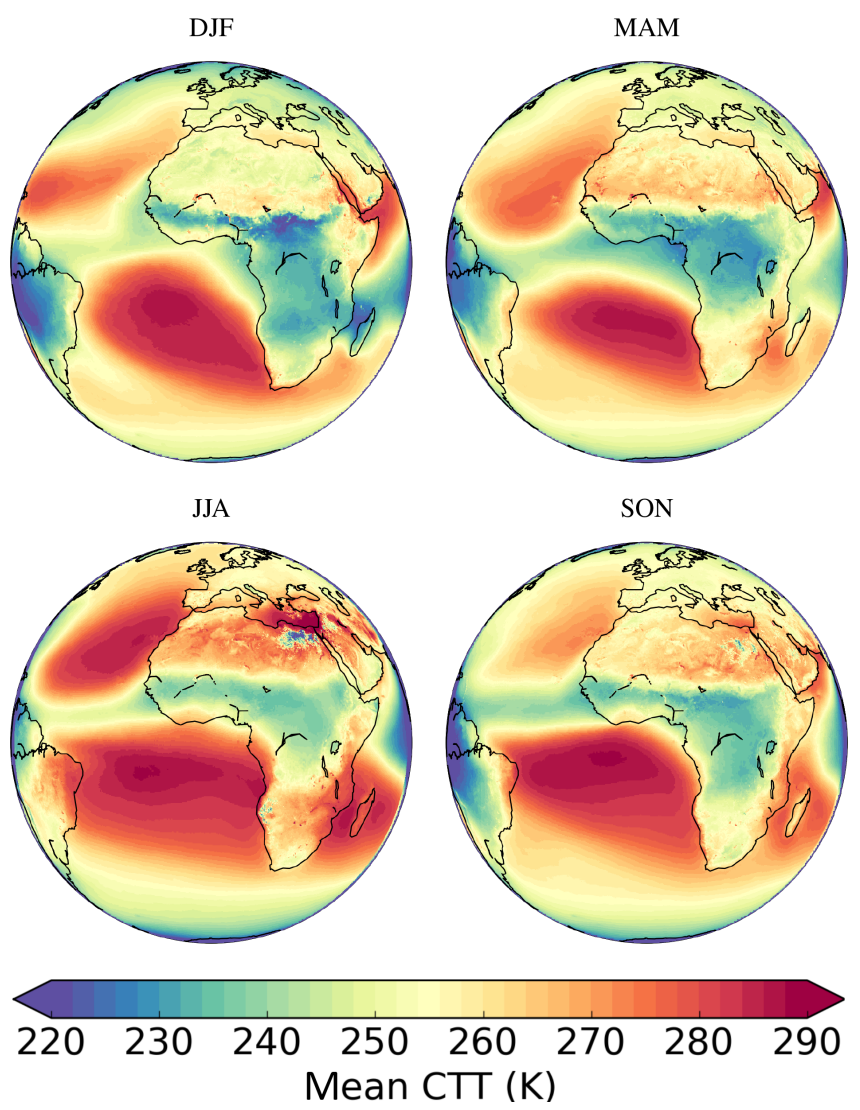

Figure 1. Seasonal mean SEVIRI cloud top temperatures for the period 2005-2015.

rithm. For clarity, the term "SEVIRI" will be used to refer to this dataset hereafter.

\section{Results}

\subsection{Mean cloud top temperature}

Seasonal mean SEVIRI cloud top temperatures for the period 2005-2015 are shown in Fig. 1, while the total number of SEVIRI cloud top temperature retrievals is shown in Fig. 2. As expected, the warmest CTTs are observed over the ocean, and the coldest over land, where a strong diurnal cycle in land surface temperatures drives convective initiation. Typical cloud regime patterns showing deep convection over land in the region of the Intertropical Convergence Zone (ITCZ), shallower convection over the central Atlantic Ocean in the trade wind convergence zone, and stratocumulus cloud in the southeast Atlantic Ocean are evident. Cloud is most frequent over land, in the region of the ITCZ, and over the southeast Atlantic Ocean, particularly in September, October, and November (SON) (Fig. 2). Very few clouds are observed over the Sahara and parts of the Middle East, as well as in southern Africa during June, July, and August (JJA) (Fig. 2). 

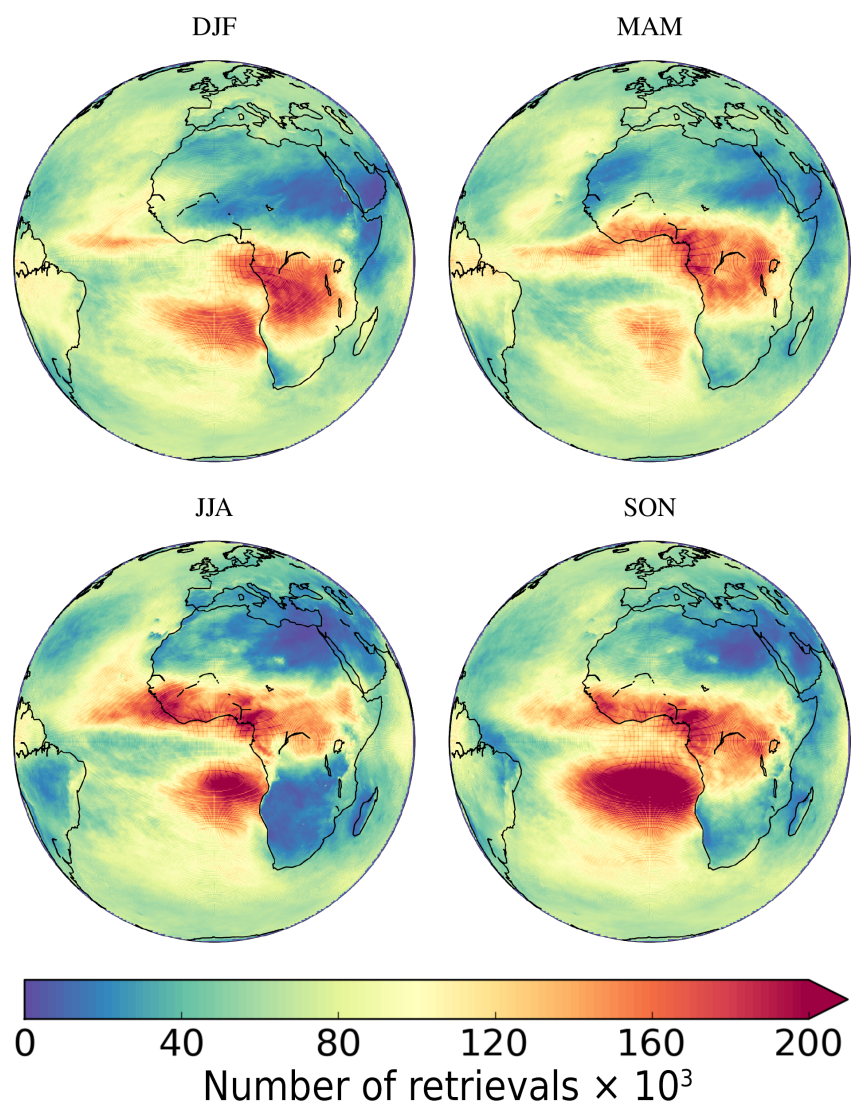

Figure 2. Spatial distributions of the total number of SEVIRI cloud top temperature retrievals available from the CLAAS-2 dataset during the period 2005-2015. Values are shown for each season.

Seasonal patterns in convection, driven by the movement of the ITCZ (Waliser and Gautier, 1993; Yang and Slingo, 2001; Schröder et al., 2009)) can be clearly seen. In December, January, and February (DJF), the ITCZ is shown as a band of cold cloud running from the southern Indian Ocean through central Africa (where it crosses the Equator) and the west African coast before falling back south of the Equator, towards South America. In JJA, the ITCZ traces a more northerly position, largely located north of the Equator, stretching from the Gulf states through the Sahel and trade wind convergence region towards Venezuela.

In all seasons, regions with the coldest clouds have seasonal mean CTTs of between 200 and $240 \mathrm{~K}$, indicative of persistent deep convection in these areas. These clouds are concentrated in central Africa, the Amazon, and the west African coast. The warmest CTTs are found in the region of persistent stratocumulus cloud in the southeast Atlantic Ocean, where seasonal mean CTTs range between 270 and $290 \mathrm{~K}$.

The position of the central Atlantic trade wind convergence zone is closely related to the seasonal movement of the ITCZ. Cloud top temperatures in this region fall to between 230 and $250 \mathrm{~K}$, with particularly cold clouds observed in March, April, and May (MAM) and SON due to the passage of the ITCZ. This indicates the presence of shallower convective cloud, initiated by the convergence of Northern and Southern Hemisphere winds.

The concentration of cold clouds in central and west Africa suggests that the absolute diurnal cycle of convection (the mean change in CTT throughout the day) may be strongest in these regions. However, this pattern could be the result of either the strong vertical development of deep convective clouds throughout the day or the continuous presence of cold cloud. Before attempting to quantify the diurnal cycle of CTT at cloud top using SEVIRI CTT data however, it is necessary to consider the impact of spatial and diurnal variations in retrieval biases, which may have a significant impact on the diurnal cycle derived from this dataset.

\subsection{Evaluation of SEVIRI cloud top temperature retrievals with CALIOP data}

Biases in the CTT retrieval can be expected to display significant temporal and spatial variation. For example, Figs. 1 and 2 show clear spatial and seasonal patterns in cloud occurrence and cloud top temperature, which is likely indicative of variations in cloud type, particularly in the vicinity of the ITCZ. Surface emissions of longwave radiation also display spatial and temporal variations, particularly over land (Harrison et al., 1990; Wild et al., 2014). The implications of cloud type and land surface emissivity for the accuracy of cloud top property retrievals from SEVIRI were discussed in Sect. 1.

This study considers the implications of both the spatial and diurnal variability in the retrieval bias for the accuracy of diurnal cycle measurements across the SEVIRI disc. To this end, 1 year of SEVIRI and CALIOP CTT retrievals were compared across the SEVIRI disc. This analysis was carried out using data from 2007, the first full year for which CALIOP data are available. Data were collocated for a single year of the 12-year CLAAS-2 dataset, balancing the need to process sufficient data points to be able to examine the spatial variability of retrieval bias with the large computational expense of collocating two large datasets.

\subsubsection{Collocation}

Although CALIOP is in Sun-synchronous orbit, gathering data only at 13:30 and 01:30 local solar time (LST) (Winker et al., 2006), it uses active measurements to observe $\mathrm{CTH}$, and hence CTT, with a vertical resolution of between 30 and $60 \mathrm{~m}$. It is therefore an excellent dataset for assessing the accuracy of SEVIRI cloud top retrievals. CALIOP also offers the advantage of a long-running dataset (2006-present) and global coverage, allowing data to be compared across the entire SEVIRI disc over a long period of time.

The CALIOP dataset used in this study is the same product used in the CLAAS-2 validation report (Benas et al., 2016), the Lidar, Level 2, $5 \mathrm{~km}$ Cloud Layer, Validated Stage 1 
Version 3 product (CAL LID L2 05kmCLay-ValStage1-V301; NASA, 2013; CALIPSO Science Team, 2015). CALIOP CTH is accurate to within $30 \mathrm{~m}$ between the surface and $8.2 \mathrm{~km}$, and to within $60 \mathrm{~m}$ between 8.2 and $20.2 \mathrm{~km}$ above mean sea level (NASA, 2013). The dominant uncertainties in the vertical placement of CALIOP's cloud layers are noise in the backscatter signal and imperfect correction of the attenuation from overlying features (Vaughan et al., 2005), although, as only top-level features are used here, this last point is not relevant to this study. Due to high noise levels caused by solar background signals, the detection of cloud layers is more accurate during the night-time than in the daytime, although even subvisible cirrus is detectable under both day- and night-time conditions (NASA, 2013; Vaughan et al., 2005). In addition, the amount of signal averaging required before atmospheric features can be retrieved is smaller for strongly scattering features than for weakly scattering features (Vaughan et al., 2005).

CALIOP measures CTH and subsequently uses the GEOS-5 (Goddard Earth Observing System Model, Version 5) atmospheric GCM (Rienecker et al., 2008) to convert to CTT (NASA, 2013).

This conversion can be seen as a potential source of uncertainty in the CALIOP CTT representation, since the model has a $0.625^{\circ}$ longitude by $0.5^{\circ}$ latitude grid, with 42 vertical pressure levels, extending to $0.01 \mathrm{hPa}$ (NASA, 2017), compared to CALIOP's horizontal resolution of $5 \mathrm{~km}$ and vertical resolution of between 30 and $60 \mathrm{~m}$ (NASA, 2013). Additionally, rising air parcels such as those found in convective clouds) are usually warmer than the surrounding air, as represented by the grid mean temperature of the model fields.

CALIOP is capable of detecting cloud layers with optical depths of 0.01 (McGill et al., 2007; Vaughan et al., 2009). The optical depth of atmospheric layers is derived using extinction-to-backscatter ratios, which vary depending on the assessed layer type (NASA, 2011). Misclassified layer types can therefore lead to inaccurate estimates of layer optical depth.This is the dominant contributor to optical depth uncertainties.

It should also be noted that, due to the fact that the vertical resolution of CALIOP varies, layer CODs are reported for atmospheric layers with a minimum vertical height of $30 \mathrm{~m}$ below $8.2 \mathrm{~km}$ and for layers with a minimum vertical height of $60 \mathrm{~m}$ above $8.2 \mathrm{~km}$. The same COD above $8.2 \mathrm{~km}$ could therefore indicate different extinction profiles above and below $8.2 \mathrm{~km}$. However, CALIOP CODs are shown to compare well with values retrieved from MODIS, although CALIOP slightly underestimates values at lower optical depths (NASA, 2011).

SEVIRI and CALIOP data are collocated by searching for the closest SEVIRI pixel (regardless of whether this pixel contains a cloud in the SEVIRI dataset) to each CALIOP observation. A temporal collocation window, centred around the time of the CALIOP overpass and accounting for the fact that a single SEVIRI time step includes observations
Table 1. Descriptions of the seven sets of collocation criteria to be evaluated, the abbreviations by which they are referenced in the text, and the symbols by which they are referenced in plots.

\begin{tabular}{llrll}
\hline Abbreviation & Symbol & $\begin{array}{r}\text { Collocation } \\
\text { window } \\
\text { (mins) }\end{array}$ & $\begin{array}{l}\text { Layers } \\
\text { included }\end{array}$ & $\begin{array}{l}\text { COD } \\
\text { threshold }\end{array}$ \\
\hline 60-ML-0 & $\square$ & 60 & Multi- & None \\
15-ML-0 & $\times$ & 15 & multi- & None \\
60-SL-0 & $\diamond$ & 60 & Single & None \\
60-ML-03 & + & 60 & Multi- & $>0.3$ \\
60-ML-1 & $\nabla$ & 60 & Multi- & $>1.0$ \\
60-ML-2 & $\triangle$ & 60 & Multi- & $>2.0$ \\
60-SL-1 & $\bullet$ & 60 & Single & $>1.0$ \\
\hline
\end{tabular}

made over the course of a 12 min time period, is also applied. As discussed below, different temporal collocation windows were tested in order to quantify the sensitivity of the resulting bias to the size of this window.

As SEVIRI's detection efficiency decreases at low optical depths, it is necessary to exclude thin cloud layers from this comparison. Previous comparisons of SEVIRI and CALIOP data have excluded all cloud with an optical depth of less than 0.3 (Kniffka et al., 2013), 0.2, (Benas et al., 2016), and 0.1 (Stubenrauch et al., 2010; SAFNWC/MSG, 2012), while others have not excluded thin cloud at all (Reuter et al., 2009). In this analysis, mean statistics were calculated for a number of different collocation criteria. Due to the computational expense of collocating the datasets, different collocation criteria were tested using data for every 10th day in 2007.

Table 1 contains information on the seven different sets of collocation criteria tested. It indicates the maximum time window during which retrievals could be collocated, whether multi-layer clouds were included in the comparison, and what COD threshold was used. Each set of criteria is identified by an abbreviation, which we use to refer to individual scenarios in the text, and by a symbol, which we use to refer to scenarios in the figures.

The mean bias and RMSE for each of the collocation criteria in Table 1 are shown in Fig. 3. Statistics are plotted separately for all collocated data points, land retrievals and ocean retrievals. The number of SEVIRI CTT retrievals collocated with CALIOP for each of the sets of criteria and the number of land and ocean retrievals are shown in Fig. 4.

Adjusting the maximum time window for collocation from 60 to 15 min (60-ML-0 and 15-ML-0; see Table 1) does not have a large effect on the mean bias and RMSE (Fig. 3) or on the spatial distribution of the biases (Appendix A). However, Fig. 4 shows that a $15 \mathrm{~min}$ collocation window reduces the number of collocated retrievals by $50 \%$. A temporal collocation window of $60 \mathrm{~min}$ was therefore chosen for this analysis.

The effects of applying different COD thresholds (60-ML0, 60-ML-03, 60-ML-1, 60-ML-2; in order to account for differences in the sensitivity of the SEVIRI and CALIOP 


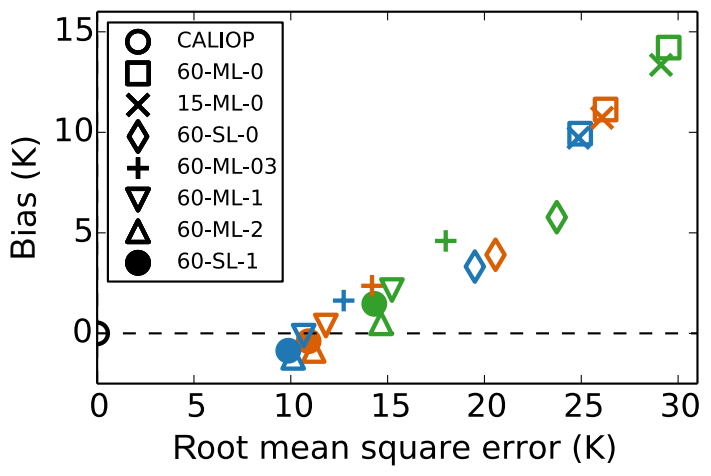

Figure 3. Bias (SEVIRI minus CALIOP CTT) versus root mean square error of SEVIRI cloud top temperature retrievals. Symbols refer to the different sets of collocation criteria, defined in Table 1. Green symbols show retrievals over land, blue over ocean, and orange over both. The "CALIOP" point on the left-hand side indicates where a retrieval which perfectly reproduces the CALIOP observations would be located.

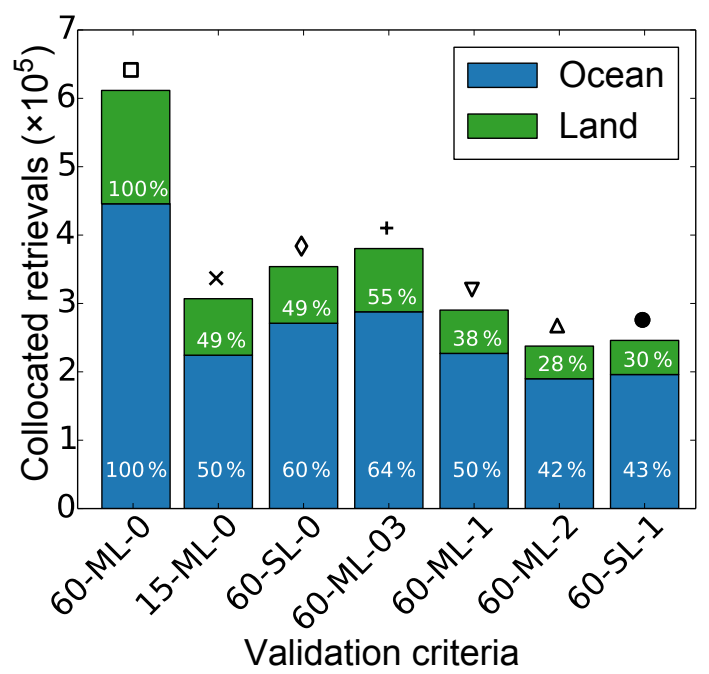

Figure 4. Number of SEVIRI and CALIOP retrievals collocated in 2007 for each of the collocation criteria defined in Table 1. Collocation criteria are identified by both text abbreviation and symbol. Colours show the division between land (green) and ocean (blue) retrievals. Percentages show what fraction of the total number of available retrievals are processed for each set of collocation criteria.

instruments to low cloud optical depths) were also considered. However, these thresholds are only able to remove biases due to the fact that CALIOP is sensitive to optically thin cloud layers which SEVIRI does not detect. It cannot affect biases between the radiometric cloud top observed by SEVIRI and the physical cloud top observed by CALIOP, discussed in Sect. 1. Thresholds were applied to the top cloud layer from the CALIOP product, using COD as measured by CALIOP using backscatter from the $532 \mathrm{~nm}$ band. Scenes for which this top layer did not meet the threshold value were excluded from the analysis. This differs from the approach im- plemented by Benas et al. (2016), although it does not lead to a large difference in the spatial distribution of the mean biases (Appendix B).

The mean bias for combined land and ocean data is reduced from $11 \mathrm{~K}$ when no COD threshold is used to $2.4 \mathrm{~K}$ when a threshold of 0.3 is used (Fig. 3). This is further reduced to $0.4 \mathrm{~K}$ for a threshold of 1 and -0.9 for a threshold of 2. Similar decreases in the RMSE were observed (Fig. 3).

The total mean and ocean-only biases are negative for the 60-ML-2 collocation criteria, while the land values display a slight positive bias (Fig. 3). This is due to the fact that the majority of the clouds in this dataset are located in the southeast Atlantic Ocean (Fig. 5), a region of prevalent subtropical subsidence inversions. In the presence of a low-level thermal inversion there are two possible solutions when using observed brightness temperatures to infer the vertical placement of cloud tops. As explained in Sect. 2, the SEVIRI retrieval algorithm (NWC SAF/MSGv2012) places the cloud top for low clouds at the pressure level which corresponds to the best fit between observed and simulated brightness temperatures. In cases of low-level thermal inversions, the SEVIRI retrieval generally places the cloud above the thermal inversion (Derrien, 2013) and may therefore underestimate CTT in these areas. However, the CALIOP retrieval of CTT is based on direct observations of CTH and is therefore not subject to uncertainty with respect to the vertical placement of the cloud top in the first place (NASA, 2013; Hamann et al., 2014). However, the vertical resolution of the model fields used to convert CALIOP CTH to CTT is relatively coarse, which may introduce some uncertainty in the CALIOP values themselves. If the latter effect is small, the difference in approach to the vertical placement of clouds in the presence of inversions will result in a systematic negative bias in the SEVIRI retrieval in this region.

Finally, the impact of excluding multi-layer cloud from the collocation is considered (60-ML-0, 60-SL-0, 60-ML1, and 60-SL-1; Table 1). Excluding multi-layer cloud when no COD is used (60-SL-0) results in the mean bias falling from 11.1 to $3.9 \mathrm{~K}$ and the mean RMSE falling from 26.3 to $20.6 \mathrm{~K}$ (Fig. 3), indicating that, in the case of multi-layer cloud scenes, observed cloud top brightness temperatures are likely contaminated by longwave emissions from lower-level clouds. However, once a COD threshold of 1.0 is applied, excluding multi-layer cloud (60-SL-1) results in a much smaller change in the bias from 0.4 to $-0.4 \mathrm{~K}$, with the mean RMSE falling from 11.8 to $10.9 \mathrm{~K}$ (Fig. 3). This shows that, when the top cloud layer observed by CALIOP has a COD greater than 1, the brightness temperatures observed by SEVIRI are no longer significantly contaminated by longwave emissions from lower-level clouds. CALIOP scenes containing multiple layers of cloud were therefore included.

To summarize, for all further analysis presented in this paper, we collocated SEVIRI and CALIOP data using the 60-ML-1 criteria, consisting of a 60 min collocation window, inclusion of scenes with multiple layers of cloud, and 
a COD threshold of 1.0. The resulting cloud top temperature retrievals from SEVIRI and CALIOP were compared for the full year of 2007, as follows. For each 5 by $5 \mathrm{~km}$ CALIOP pixel within the SEVIRI disc,

- the highest reported CALIOP cloud layer was selected;

- the SEVIRI pixel with the closest latitude and longitude to those of the CALIOP pixel was selected;

- for this pixel, the nearest SEVIRI retrieval in time (within the allowed 60 min time window) was identified;

- if multiple CALIOP retrievals fell within a single SEVIRI pixel, the values were averaged (this was only necessary towards the edges of the disc, beyond approximately $50^{\circ} \mathrm{E}$ and $50^{\circ} \mathrm{W}$ );

- the retrieval bias (calculated as SEVIRI minus CALIOP CTT) was calculated for each instance of collocated data.

\subsubsection{Retrieval biases}

The annual mean bias in SEVIRI CTT, calculated across the entire SEVIRI disc from January to December 2007, combining both daytime and night-time conditions, is $0.44 \mathrm{~K}$ with a standard deviation of $11.7 \mathrm{~K}$ (Table 2). This is smaller than the $2.1 \mathrm{~K}$ mean bias calculated by Benas et al. (2016). The difference is likely due to the fact that a less stringent COD threshold of 0.3 was applied by Benas et al. (2016).

Statistics calculated over a variety of regions and conditions show that the biases between SEVIRI and CALIOP CTTs (SEVIRI minus CALIOP) are normally distributed, although in the case of data over the oceans this distribution is skewed slightly towards negative values. This skew is likely due to the large number of slightly negative values found in the southeast Atlantic Ocean, as discussed in Sect. 3.2.1. These distributions show small mean biases and large standard deviations. Over the ocean the mean bias in SEVIRI CTT is smaller, at $-0.12 \mathrm{~K}$, with a standard deviation of $10.5 \mathrm{~K}$, but over land the mean bias rises to $2.38 \mathrm{~K}$, with a standard deviation of $14.9 \mathrm{~K}$ (Table 2).

It should also be noted that the sign of the mean bias is negative over the ocean for both daytime and night-time retrievals, although the bias is always positive over land. As discussed in Sect. 2, even once clouds with a low optical depth are filtered out, observations from SEVIRI are expected to detect a warmer radiometric CTT than the higher, and therefore colder, physical cloud top heights measured by CALIOP.

The spatial distribution of the number of fully cloudy pixels for which SEVIRI retrieved a CTT value and for which a corresponding CALIOP value was available during 2007 is shown in Fig. 5. Collocated retrievals are concentrated in the southeast Atlantic Ocean (Fig. 5), an area of almost perpetual
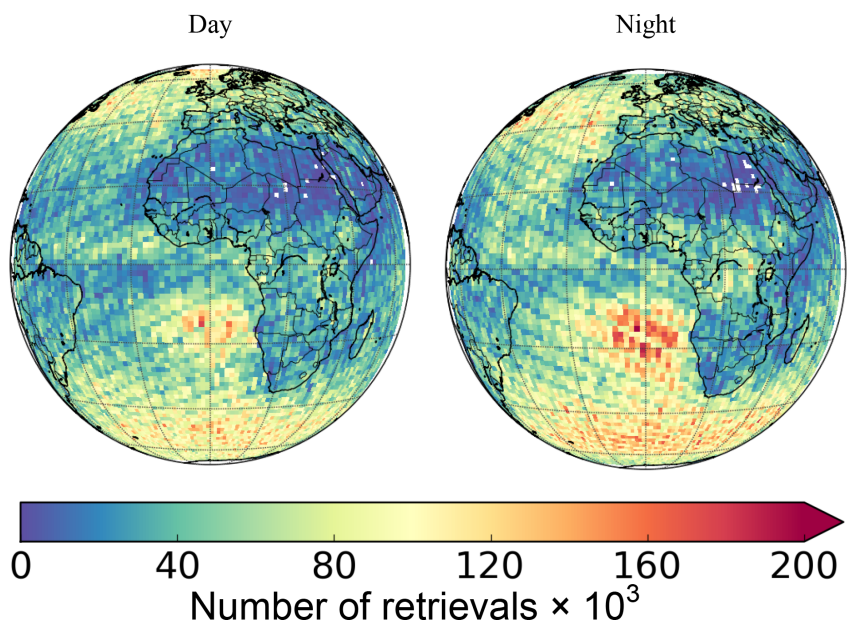

Figure 5. Spatial distribution of the number of collocated SEVIRI and CALIOP retrievals in 2007, shown separately for daytime and night-time conditions.

cloudiness, where atmospheric inversions are prevalent. The negative biases over the ocean are again due to the different retrieval processes for SEVIRI and CALIOP with regard to the vertical placement of clouds in regions of atmospheric inversions (as discussed in Sect. 3.2.1).

Figure 6 shows the spatial distribution of mean SEVIRI minus CALIOP CTT for daytime, night-time, day- and nighttime combined, and the difference between night- and daytime biases. It can immediately be seen that for both dayand night-time retrievals, there are large areas of very high mean bias, although, due to compensating biases, these are obscured in some areas when day- and night-time biases are plotted together. However, many of the areas of high bias correspond to regions with few cloud retrievals, such as the Sahara (Fig. 5).

SEVIRI is shown to generally overestimate CTT over land, by approximately $10-20 \mathrm{~K}$ during the day and $15-25 \mathrm{~K}$ (or more) at night (Fig. 6). These values are larger than those reported by Benas et al. (2016), who do not consider dayand night-time biases separately. However, these biases are in agreement with the expected discrepancy of $0.5-3.0 \mathrm{~km}$ (approximately $3-20 \mathrm{~K}$ assuming a $6.5 \mathrm{~K} \mathrm{~km}^{-1}$ lapse rate) between radiometric and physical cloud top height found by Sherwood et al. (2004), Minnis et al. (2008), and Stubenrauch et al. $(2010,2013)$ in the case of high clouds.

Biases are relatively small over the majority of the ocean. CTT is underestimated by $5-10 \mathrm{~K}$ over large areas of the Atlantic Ocean, while in other areas, such as the region of trade wind convergence, SEVIRI overestimates CTT by $5-15 \mathrm{~K}$ (Fig. 6), which is within the expected range of discrepancy due to the differences between the radiometric and physical cloud top height (Sect. 1).

The large areas of slightly negative bias in the Atlantic Ocean correspond to the areas of persistent atmospheric in- 
Table 2. Summary of evaluation results for the 60-ML-1 collocation criteria, showing number of collocated SEVIRI retrievals, mean bias (SEVIRI minus CALIOP CTT), and standard deviation of the bias. Statistics are reported separately for day, night, land, and ocean retrievals.

\begin{tabular}{llrrr}
\hline Surface type & Time of day & $\begin{array}{r}\text { Number of } \\
\text { retrievals }\left(10^{6}\right)\end{array}$ & $\begin{array}{r}\text { Mean bias } \\
(\mathrm{K})\end{array}$ & $\begin{array}{r}\text { Standard deviation } \\
\text { of bias (K) }\end{array}$ \\
\hline \multirow{3}{*}{ Land and ocean } & Day and night & 2.79 & 0.44 & 11.7 \\
& Day & 1.34 & 0.05 & 12.2 \\
& Night & 1.45 & 0.80 & 11.2 \\
\hline \multirow{3}{*}{ Land } & Day and night & 0.63 & 2.38 & 14.9 \\
& Day & 0.32 & 0.72 & 16.0 \\
& Night & 0.31 & 4.11 & 13.5 \\
\hline \multirow{3}{*}{ Ocean } & Day and night & 2.16 & -0.12 & 10.5 \\
& Day & 1.02 & -0.16 & 10.7 \\
& Night & 1.14 & -0.10 & 10.4 \\
\hline
\end{tabular}
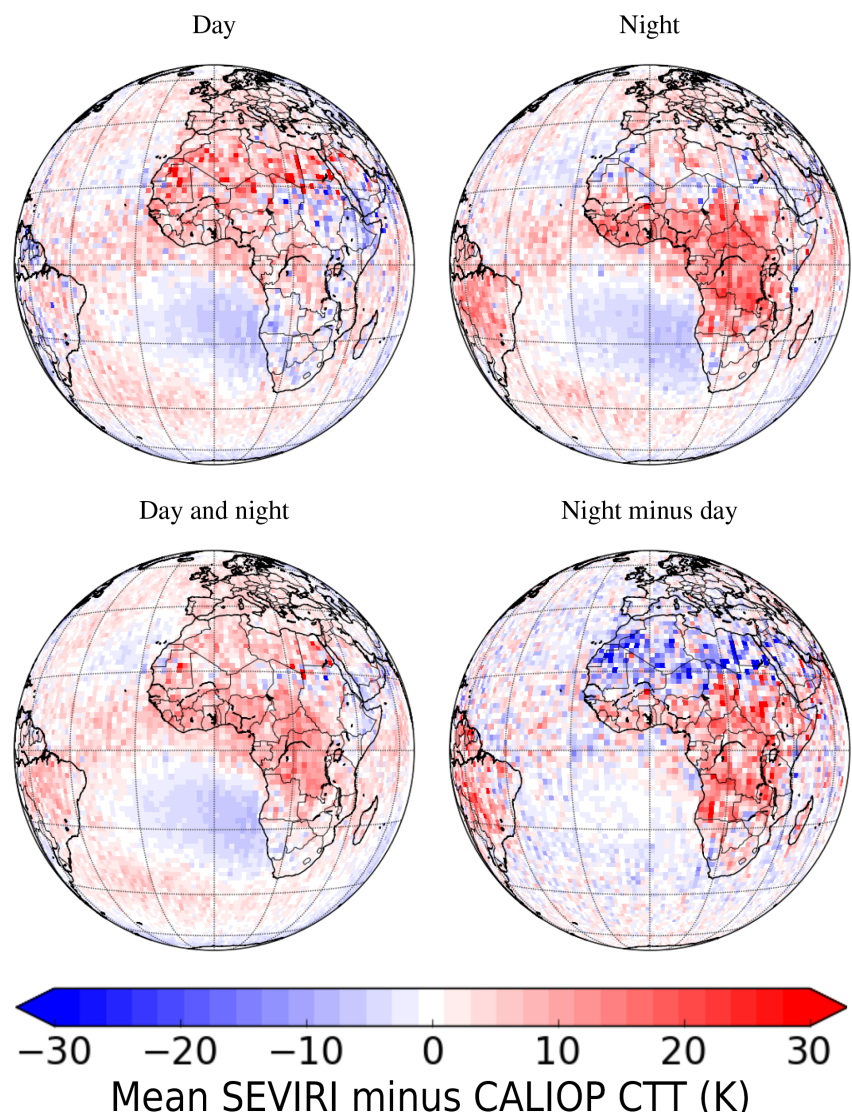

Figure 6. Spatial distribution of the bias in SEVIRI cloud top temperature retrievals during 2007. Biases are shown for the day (13:30 LST CALIOP overpass), night (01:30 LST CALIOP overpass), mean of both day and night biases, and difference (night minus day) between night- and daytime biases.

version. As explained previously, the small systematic bias in the SEVIRI CTT retrieval in this region is due to its treatment of subsidence inversions. As can be seen from Fig. 5, the majority of the collocated retrievals are located in this region. Therefore, the mean biases presented in Table 2 are heavily weighted towards the small negative biases in this region.

The difference in the magnitude of the biases over land and ocean is likely due to differences in the most common cloud regimes observed over land and ocean (Yang and Slingo, 2001; Schröder et al., 2009). As suggested by Sherwood et al. (2004) and Stubenrauch et al. (2013), the differing extinction profiles and vertical heights of convective and stratiform clouds result in larger differences between the radiometric and physical cloud top for tall convective clouds.

Unfortunately, it is not possible to fully characterize the diurnal variation in bias, as CALIOP data are only available for comparison at 01:30 and 13:30 LST. However, the two CALIOP overpasses can give at least an estimate of the potential size of this variation. For the purposes of this study, a bias in CTT which remained constant throughout the day would not be a barrier to quantifying either the amplitude of the diurnal cycle in CTT or the average time of minimum CTT. However, the fact that biases can change dramatically from the day- to night-time overpasses of CALIOP is more problematic.

Both the mean values and the spatial distribution of the biases change significantly from day to night. Differences between mean night-time and daytime biases in the SEVIRI CTT retrieval can be as large as $30 \mathrm{~K}$ in some areas (Fig. 6). There are strong positive differences over sub-Saharan Africa and South America, with strong negative differences over the Sahara (although, as discussed above, there are very few CTT retrievals in the Sahara). Differences between night- and daytime biases are generally smaller over the ocean and over Europe. In areas where the difference between daytime and night-time biases (Fig. 6) is greater than or equal to the observed magnitude of the diurnal cycle in cloud top temperature, the diurnal cycle observed from the retrieval may be a product of diurnal variability in the accuracy of the retrieval. It will therefore be necessary to consider the diurnal vari- 


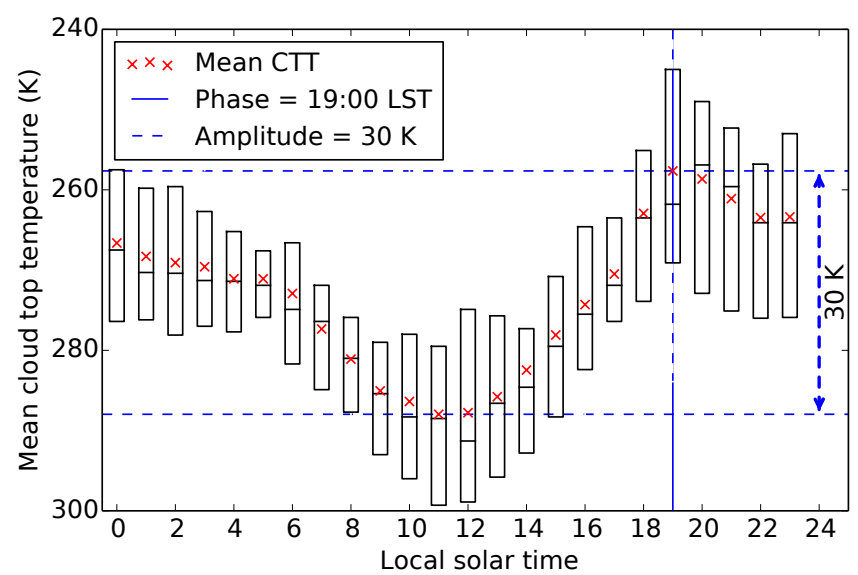

Figure 7. Seasonal mean climatological (September, October, and November 2005-2015) diurnal cycle of cloud top temperature at $3.1^{\circ} \mathrm{S}, 16.4^{\circ} \mathrm{E}$ (western Democratic Republic of the Congo; see cross in Fig. 10). Box plots are used to show the quartiles the shapes of the distribution for each mean point. The amplitude of the diurnal cycle (defined as minimum minus maximum CTT) and the phase (defined as the local solar time (LST) of minimum CTT) are also illustrated.

ability in retrieval bias when quantifying the diurnal cycle of cloud top temperature.

\subsection{Diurnal cycle of CTT}

The CLAAS-2 MMDC product was used to calculate 3month mean diurnal cycles of cloud top temperature across the SEVIRI disc. Data were averaged for the period 20052015 to produce a diurnal cycle with a temporal resolution of $1 \mathrm{~h}$ on a spatial grid of $0.25^{\circ}$. Ten years of data were required in order to ensure that each regional hourly mean value was calculated using a large number (more than 1000) of CTT retrievals from the 10-year period, particularly over land, where cloud retrievals were relatively sparse. There were a few regions where it was not possible to reach this threshold; these are shaded in Figs. 8 and 9.

An example of the resulting diurnal cycle in cloud top temperature is shown in Fig. 7 for a grid box centred on $3.1^{\circ} \mathrm{S}, 16.4^{\circ} \mathrm{E}$ (western Democratic Republic of the Congo; see cross in Fig. 10) for the months of SON. The amplitude of the diurnal cycle in CTT was calculated as the maximum minus minimum diurnal mean cloud top temperature, as shown by the arrow indicating an amplitude of $30 \mathrm{~K}$. The local solar time of the minimum cloud top temperature was defined as the time at which the minimum daily mean CTT occurred, as shown by the dashed line at 19:00 LST.

While the averaging process produced a coherent diurnal cycle in the majority of cases, the calculated diurnal cycle remained noisy in a few areas, particularly during seasons when very few clouds were retrieved. The number of CTT retrievals is greatest over areas of the ocean where large, ho-
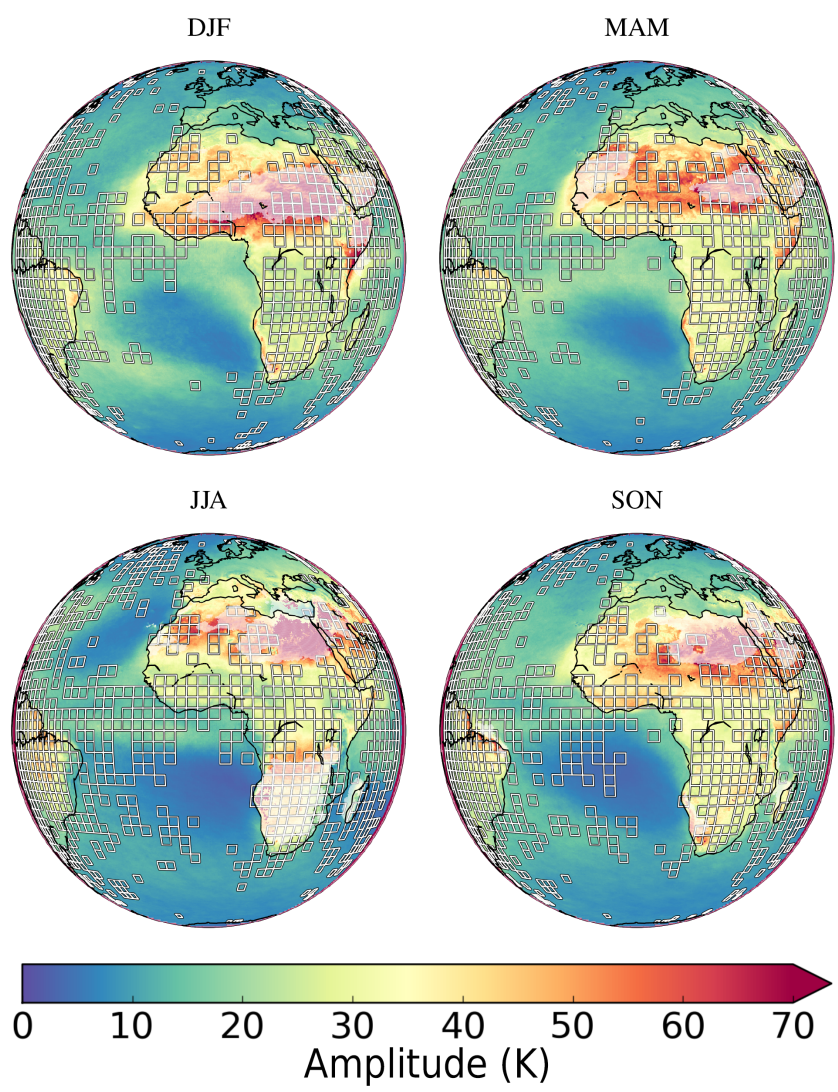

Figure 8. Seasonal mean amplitude of the diurnal cycle in SEVIRI cloud top temperature for the period 2005-2015. The white overlay indicates regions where retrievals are available for fewer than $15 \%$ of the processed time steps. Squares indicate regions where the ratio of the amplitude of the diurnal cycle in CTT to the diurnal variability in CTT retrieval bias is less than 5 .

mogeneous stratiform cloud fields result in a large number of cloud-filled pixels and hence a large number of SEVIRI CTT retrievals, and in the region of the ITCZ, where convective cloud is concentrated (Fig. 2). In areas with very few cloud retrievals, such as the Sahara in all seasons and parts of southern Africa in JJA (Fig. 2), it will not be possible to accurately calculate a diurnal cycle of convection.

Maps of the amplitude of the diurnal cycle in SEVIRI cloud top temperature (Fig. 8), calculated as shown in Fig. 7, show the smallest amplitudes located over the southeast Atlantic Ocean in all seasons. Over the course of a typical day, stratocumulus cloud tops vary by less than $5 \mathrm{~K}$ in this region. Amplitudes increase to between 20 and $30 \mathrm{~K}$ in the trade wind region, where there are more convective clouds. Over Africa and South America amplitudes generally range between 20 and $50 \mathrm{~K}$, with the seasonal changes tracking the movement of the ITCZ, seen as a migrating band of cold cloud tops in Fig. 1. The diurnal cycle is smaller in Europe, where amplitudes range from $15 \mathrm{~K}$ in the north during DJF to $50 \mathrm{~K}$ in the Mediterranean during JJA. 
For illustrative purposes, amplitudes of the diurnal cycle in CTT were plotted for areas with few CTT retrievals, but regions with retrievals at less than $15 \%$ of the processed time steps are indicated (Fig. 8). With the exception of southern Africa in JJA, these regions correspond to areas of desert, and calculated amplitudes tend to be very large. Amplitudes exceed $60 \mathrm{~K}$ in areas of the Sahara and Namibian deserts in all seasons, as well as in Somalia during the December-March dry season (Higgins et al., 1978) and southern Africa during the May-September dry season (Higgins et al., 1978; Fig. 8). The large amplitudes observed in these areas are likely to be caused by a mixture of insufficient data (Fig. 2) and, particularly in the Sahara, a large variation in the size of the retrieval bias between night- and daytime conditions (Fig. 6).

In order to consider the effects of systematic differences in day- and night-time CTT retrieval biases in the SEVIRI dataset, the ratio of the amplitude of the diurnal cycle (Fig. 8) to the diurnal variability in the retrieval bias (Fig. 6) was calculated. In regions where this ratio is low, differences between systematic retrieval biases under day- and night-time conditions may contribute strongly to the amplitude of the observed diurnal cycle in cloud top temperatures. A threshold value of 5 was chosen for this ratio, as indicative of regions in which observed diurnal cycles in CTT may simply be artefacts of the diurnal variation in retrieval errors. Areas for which the ratio falls below this threshold are indicated in Fig. 8.

Maps of the phase of the diurnal cycle, defined at each grid box as the local solar time at which the minimum 3-monthly mean CTT occurs (Fig. 7), are shown in Fig. 9. Regions with few clouds or where diurnal variability in retrieval bias may significantly contribute to the observed diurnal cycle are illustrated in Fig. 9, as described for Fig. 8.

Over large areas of the ocean, minimum CTTs are observed at around 16:00 LST. In the southeast Atlantic however the minimum is observed in the morning, at around 09:00 LST.

In South America, minimum CTT generally occurs at around 20:00 LST. Over sub-Saharan Africa and Europe the minimum is generally observed at around 16:00 LST, with some areas - particularly west Africa, the Sahel, and parts of the Congo Basin - showing later peaks at around 18:00 LST. These later peaks broadly track the movement of the ITCZ (Fig. 1) and could be due to more vigorous convection, persisting until later in the day. It could also be due to a mixture of different convective cloud types, including organized MCSs which can persist until the early morning and more isolated local convective cells which peak in the afternoon (Rickenbach et al., 2009; Pfeifroth et al., 2016).

Areas with few cloud retrievals, such as the Sahara in all seasons and southern Africa in JJA, are noisier (Fig. 9). This may be due to the fact that there are simply not enough data in these regions to meaningfully diagnose the phase of the diurnal cycle in CTT. However, the regions with the fewest retrievals (Figs. 5 and 9) do not match exactly the regions
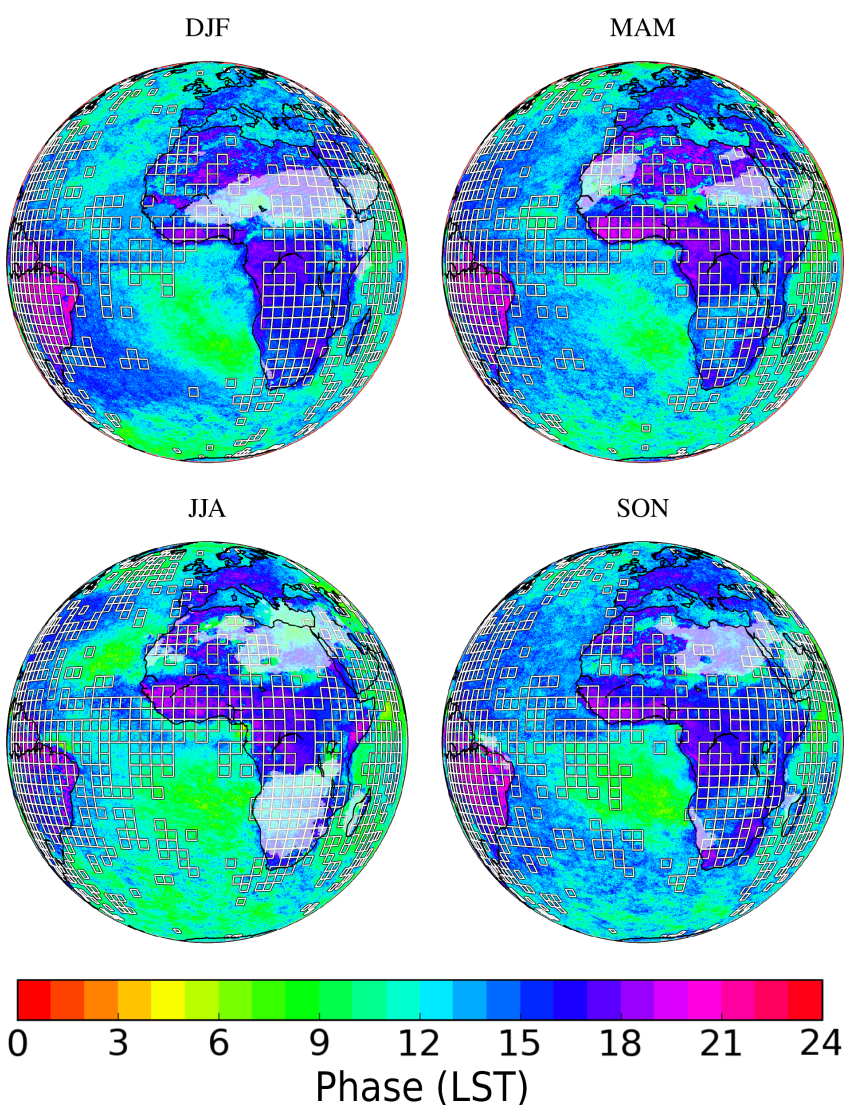

Figure 9. Seasonal mean phase (local solar time of minimum climatological mean CTT) of the diurnal cycle in cloud top temperature for the period 2005-2015. The white overlay indicates regions where retrievals are available for fewer than $15 \%$ of the processed time steps. Squares indicate regions where the ratio of the amplitude of the diurnal cycle in CTT to the diurnal variability in CTT retrieval bias is less than 5 .

of noise in Fig. 9. This indicates that the noise may also be caused by a mixture of different cloud types with different diurnal cycles.

The relationship between the observed amplitude and phase of the diurnal cycle and the retrieval biases presented in Sect. 3.2 were examined in more detail over the Sahara, central Africa, and the southeast Atlantic Ocean. These areas were chosen because they all exhibit fairly consistent patterns of both retrieval bias and observed diurnal cycle properties and were designed to cover approximately $9 \times 10^{6} \mathrm{~km}^{2}$ each. They also provide examples of desert, rainforest, and ocean surface types. The locations of these three areas are illustrated in Fig. 10.

Seasonal mean SEVIRI diurnal cycles and retrieval biases for each of the regions in Fig. 10 were compared (Fig. 11). We have already shown that the SEVIRI dataset has different retrieval biases under daytime and night-time conditions (Sect. 3.2), due to differences in solar illumination, cloud types, the availability of visible-channel observations, 


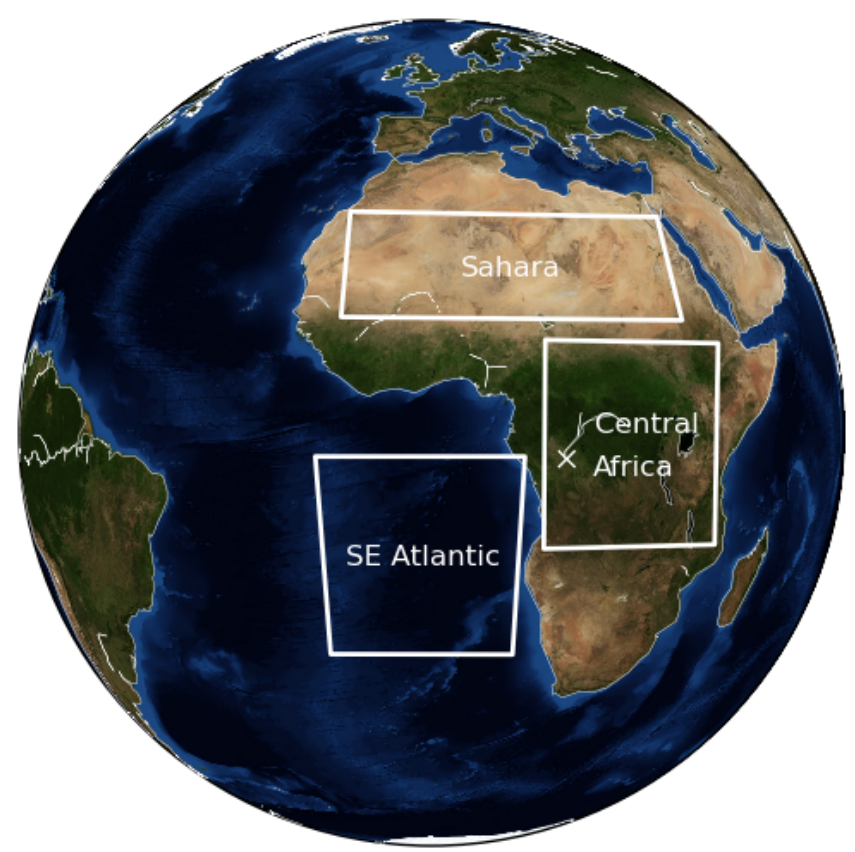

Figure 10. Map of the area observed by SEVIRI showing truecolour surfaces, major rivers, and lakes. Labelled boxes show the locations of the regions used in Fig. 11. The white cross shows the location of the data used in Fig. 7.

and subsequently the exact retrieval algorithms used. Seasonal mean times of sunrise and sunset are therefore indicated for each region, and mean retrieval biases, as calculated in Sect. 3.2 for the year 2007, are shown for both day- and night-time CALIOP overpasses.

In the southeast Atlantic Ocean, the bias is shown to be small, with no apparent diurnal cycle in the bias (Fig. 11). Mean CTTs reach a minimum at around 09:00 LST and persist until 16:00 LST in the DJF and MAM seasons. In JJA the cold clouds are more short-lived, and in SON cloud top temperatures remain constant throughout the day.

In the Sahara, the amplitude of the diurnal cycle is almost $20 \mathrm{~K}$, with a small diurnal cycle in the bias of around $5 \mathrm{~K}$ (Fig. 11). The warmest CTTs are observed at 05:00 and at noon LST, with the coldest cloud at 07:00 and 18:00 LST. Although the diurnal cycle in the bias is less than the amplitude of the diurnal cycle, the bias results in cloud top temperatures retrieved during the day being too warm, indicating that a significant fraction of the amplitude observed over the Sahara may be due to differences between the day- and nighttime conditions and hence the differences in the retrieval algorithms applied. Sudden changes in mean CTT around the times of sunrise and sunset in the Sahara are also seen in Fig. 11. In all seasons there is a secondary minimum in cold cloud top temperatures at around 06:00 LST, about an hour before sunrise. This secondary minimum may indicate the presence of MCSs, or simply a change in values due to the change in retrieval algorithm at this point.
In central Africa, the diurnal cycle in the bias is around $7 \mathrm{~K}$ and the amplitude of the diurnal cycle is around $15 \mathrm{~K}$ throughout the year (Fig. 11). The warmest cloud is observed at 14:00 LST, with the coldest cloud between 20:00 LST in DJF and 22:00 LST in JJA. There is a secondary minimum at 09:00 LST in all seasons except DJF, which may be caused by the presence of MCS, although it is also possible that this secondary peak is produced by the switch from night to daytime retrieval conditions. In contrast to the Sahara however, the diurnal cycles in retrieval bias create a smaller amplitude of the diurnal cycle in cloud top temperatures than would otherwise be observed. This size of the bias during the early morning may indicate a larger difference between the radiometric cloud top measured by SEVIRI and the physical cloud top measured by CALIOP due to differences in cloud types throughout the day. While the ratio of the diurnal cycle in mean CTT to the difference in retrieval biases is small, it appears that in this region the difference in the retrieval bias is acting to reduce, rather than increase, the observed diurnal cycle in CTT.

It is interesting to note that the broad shape of the diurnal cycle curves in the Sahara and central Africa are similar, although the post-sunrise increase in CTT is delayed in central Africa relative to the Sahara. The reasons for the time lag between diurnal cycles of CTT in central Africa and the Sahara are not known yet and will be addressed by future studies.

\section{Conclusions}

In this study we evaluated SEVIRI cloud top temperature data, as retrieved by the NWC SAF/MSGv2012 algorithm and included in the updated CLAAS-2 dataset, against CALIOP and attempted to quantify spatial and diurnal variabilities in retrieval biases. We also quantified the amplitude and phase of the diurnal cycle in cloud top temperatures observed by SEVIRI. By comparing our measurements of the diurnal cycle in mean CTT and retrieval bias, we show that diurnal variations in the retrieval bias are often of the same order of magnitude as the amplitude of the observed diurnal cycle. Areas in which there were insufficient data to accurately calculate the diurnal cycle in CTT, or in which the observed cycle was an artefact of retrieval biases, were identified.

SEVIRI and CALIOP data were collocated using a $60 \mathrm{~min}$ collocation window and a COD threshold of 1.0. Scenes with multiple layers of cloud were included. By collocating SEVIRI and CALIOP CTT retrievals for the whole year of 2007, we show that mean errors in the SEVIRI retrieval can vary from less than $5 \mathrm{~K}$ to more than $30 \mathrm{~K}$ across the SEVIRI disc, and by up to $30 \mathrm{~K}$ between the daytime and night-time overpasses of CALIOP. However, mean errors across the SEVIRI disc are small, at approximately $0.44 \mathrm{~K}$ with a standard deviation of $11.7 \mathrm{~K}$. This shows the importance of consider- 
SE Atlantic

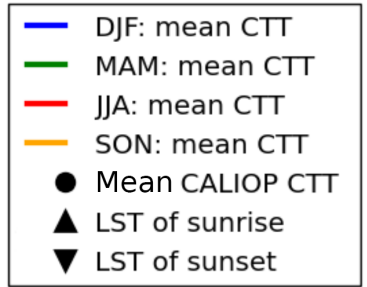

Central Africa

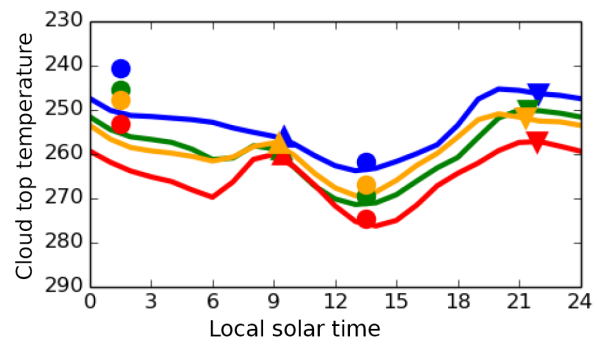

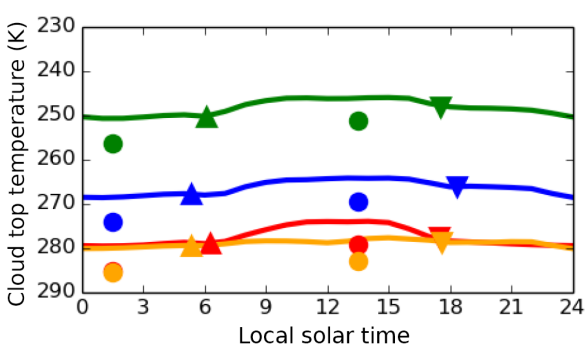

Sahara

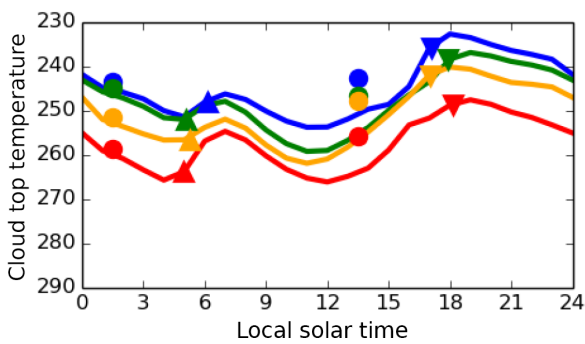

Figure 11. Seasonal mean diurnal cycles of SEVIRI CTT calculated over the period 2005-2015 (solid lines) and mean 2007 SEVIRI minus CALIOP retrieval bias (vertical distance between coloured circles and corresponding coloured lines). Biases are shown at the mean LST for the day- and night-time CALIOP overpasses. Also shown are the local solar times of sunrise (triangles) and sunset (nablas) for each region and season.

ing spatial and diurnal variations in retrieval error when using this dataset.

We believe that the difference between the radiometric cloud tops retrieved from SEVIRI and the physical cloud tops measured by CALIOP may account for a significant fraction of the biases found in this analysis. As explained in Sect. 1, previous studies indicate that biases of less than $0.5-3.0 \mathrm{~km}$ (approximately $3-20 \mathrm{~K}$ ) could potentially be explained by this difference, even for optically thick clouds. As cloud layers with an optical depth of less than 1 were not included in the comparison of SEVIRI and CALIOP CTT data, we expect biases to be largest in the case of optically thick clouds with poorly defined edges, such as glaciated clouds. In addition, the small negative bias observed over the southeast Atlantic Ocean is likely related to uncertainties introduced by the use of models to estimate the vertical placement of clouds for both SEVIRI and CALIOP datasets. We believe that biases that fall outside of both the $3-20 \mathrm{~K}$ range and the region of subsidence in the southeast Atlantic Ocean are most likely the result of other, as yet undiagnosed, errors in the SEVIRI retrievals. However, it is not within the scope of this study to identify the cause of these potential retrieval errors.

With these uncertainties in mind, the seasonal, diurnal, and spatial variations of cloud top temperatures were quantified across the SEVIRI disc. By plotting the seasonal mean amplitude and phase of the diurnal cycle in cloud top temperature, we show that SEVIRI is able to capture details of the diurnal cycle of convection across several continents. We show that the CLAAS-2 dataset measures the diurnal cycle of cloud tops accurately in regions of stratiform cloud such as the southeast Atlantic and Europe, where retrieval biases are small and exhibit limited spatial and temporal variability. Quantifying the diurnal cycle over the tropics and regions of desert is more difficult, as biases are larger and more variable.

Looking at three areas in detail (the southeast Atlantic Ocean, the Sahara, and central Africa), we analyse the relationships between the diurnal cycle in cloud top temperature and retrieval biases. We show that retrieval biases in the southeast Atlantic are small enough to detect a small but persistent diurnal cycle of approximately $5 \mathrm{~K}$ in the area, with cold clouds peaking between 11:00 and 15:00 local solar time. However, the CLAAS-2 dataset is shown to be of limited skill in measuring the diurnal cycle over the Sahara, which may be due to generally low cloud cover in desert regions and a possible dominance of optically thin clouds such as cirrus outflow from tropical convection when clouds are present. In the Sahara, variability in the bias appears to contribute to an excessively large amplitude of the diurnal cycle, with a large amount of spatial and seasonal variability in the phase. In tropical regions such as central Africa, a relatively large variability in the retrieval biases appears to dampen the signal from a strong observed diurnal cycle, with minimum cloud top temperatures occurring consistently between 20:00 and 22:00 LST. 
While this study highlights the importance of considering spatial and diurnal variations in retrieval errors when using SEVIRI data, it is also the case that observations from passive imagers in geostationary orbit provide valuable observations of the temporal and spatial variability of cloud on scales which are not available from polar-orbiting satellites such as CALIOP. We therefore see our results as guidance for the observation and modelling communities when using SEVIRI cloud top properties, particularly for studies considering the diurnal cycle of cloud top properties.
Data availability. The SEVIRI data (Finkensieper et al., 2016) are available at https://doi.org/10.5676/EUM_SAF_CM/CLAAS/ V002. The CALIOP data (CALIPSO Science Team, 2015) are available at https://doi.org/10.5067/CALIOP/CALIPSO/CAL_LID_L2_ 05kmCLay-Prov-V3-01_L2-003.01. 
Appendix A: Comparing results of different collocation time windows

The insensitivity of the calculated bias in SEVIRI CTT to a change in the collocation window used for matching to CALIOP may initially seem surprising. We collocated SEVIRI and CALIOP CTTs, for the full year of 2007, using both a $60 \mathrm{~min}( \pm 30 \mathrm{~min}$ of CALIOP overpass $)$ and a $15 \mathrm{~min}$ ( $\pm 7.5 \mathrm{~min}$ of CALIOP overpass) collocation window. This amounts to an extra $22.5 \mathrm{~min}$ between CALIOP and SEVIRI retrievals in the $60 \mathrm{~min}$ window case, as compared to the 15 min case.

There is no significant change in either the magnitude or spatial distribution of the observed biases between the two cases (Figs. 6 and A1). However, by reducing the collocation window to $15 \mathrm{~min}$, the number of collocated data points is reduced and the spatial patterns become less clear.

The biases shown in Figs. 6 and A1 consist of biases due to differences in the retrieval processes of the SEVIRI and CALIOP datasets (the retrieval bias) and to spatial and temporal differences in the scenes observed by the two instruments (the collocation bias).

If the size of the retrieval bias increased when moving from a 15 to 60 min collocation window, we would expect either the mean biases in Fig. 6 to be larger than those shown in Fig. A1 or, if the mean values are obscuring compensating errors (for example from observations before and after the CALIOP overpass), the standard deviation of the retrieval biases in the $60 \mathrm{~min}$ case to be larger than those in the $15 \mathrm{~min}$ case. However, there is little difference between the two sets of maps (Fig. A2). This indicates that the size of the collocation biases does not increase significantly when using a 60 min time window in place of a 15 min window.

On reflection, there are many reasons to think that the collocation bias may be small relative to the large retrieval biases seen in many parts of the SEVIRI disc. For example, over areas of stratiform cloud, cloud top temperature is unlikely to change significantly over the space of the extra $22.5 \mathrm{~min}$ allowed by a $60 \mathrm{~min}$ collocation window. In more convective areas, some clouds may develop significantly over the course of the larger time window, but the cloud top temperature of mature convective cloud systems and convective anvils will be more stable over time.

\section{Appendix B: Cloud optical depth threshold methodology}

When collocating SEVIRI and CALIOP retrievals of CTT, scenes observed by CALIOP were excluded if the top cloud layer had an optical depth of less than 1. This differs from the approach implemented by Benas et al. (2016), who compared CTT values for the first CALIOP layer at which the top-down, vertically integrated cloud optical depth exceeded the threshold value. The number of scenes containing cirrus

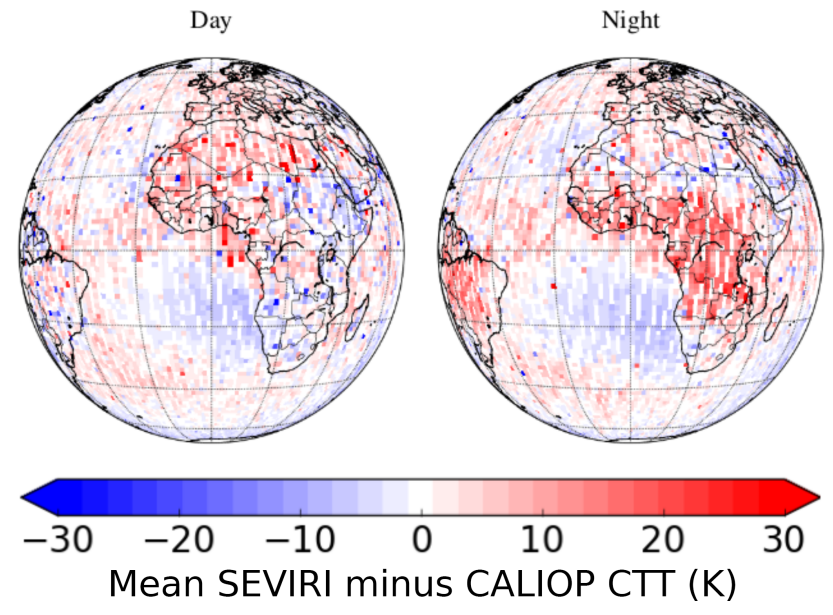

Figure A1. Spatial distribution of the bias in SEVIRI cloud top temperature retrievals during 2007, using a 15 min collocation window. Biases are shown separately for the day (13:30 LST CALIOP overpass) and night (01:30 LST CALIOP overpass).
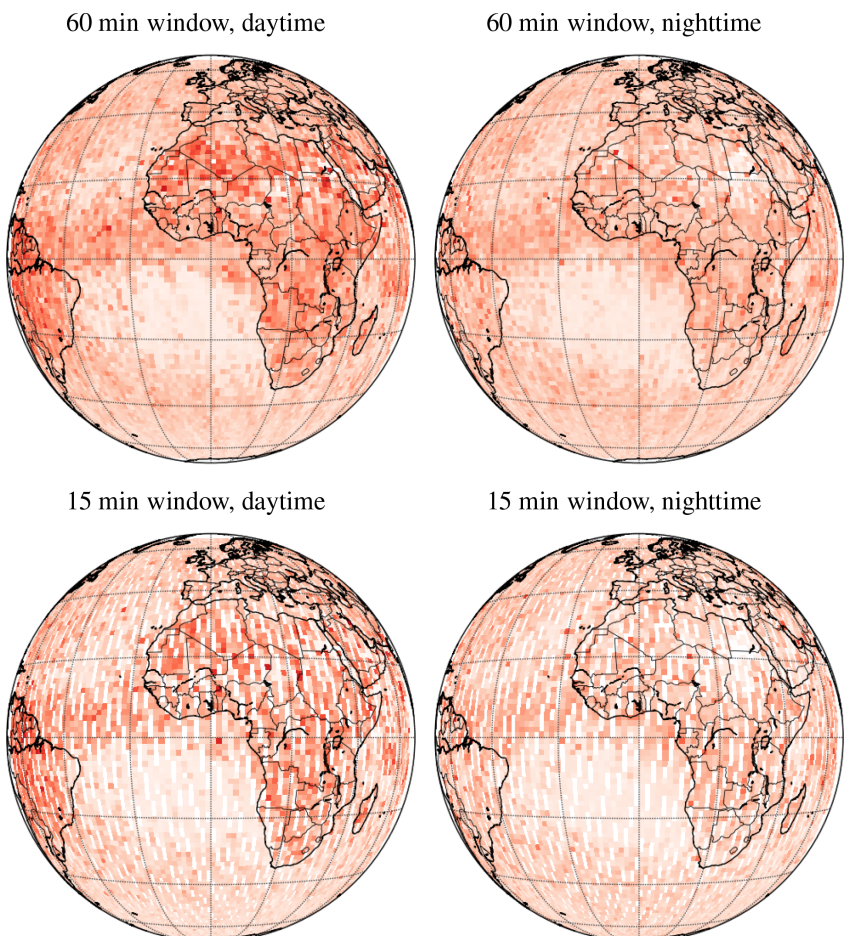

15 min window, nighttime
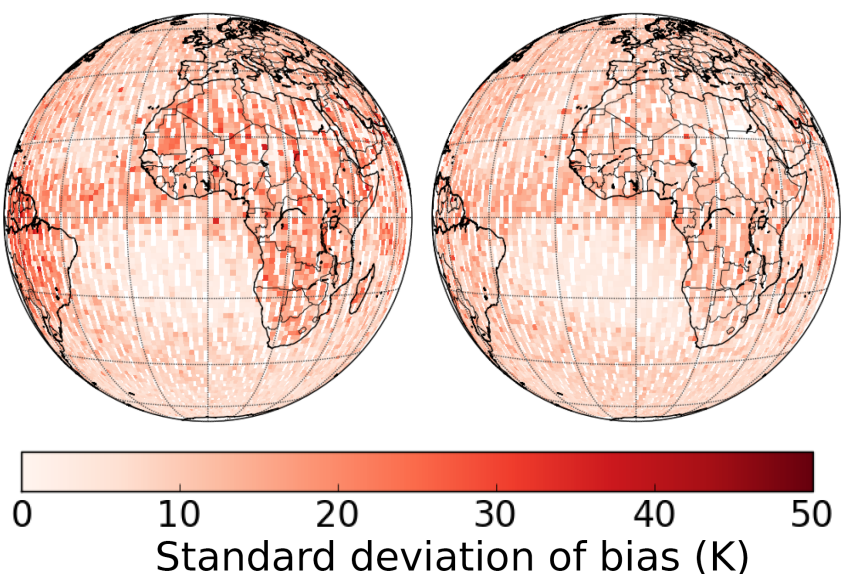

Figure A2. Spatial distribution of the standard deviation of the biases in SEVIRI cloud top temperature retrievals during 2007. Data are shown for both the daytime (13:30 LST CALIOP overpass) and night-time (01:30 LST CALIOP overpass), using a $60 \mathrm{~min}$ collocation window and a 15 min collocation window. 
cloud is therefore reduced in this analysis, compared to that of Benas et al. (2016). This is likely to increase the weighting of statistics presented in Sect. 3.2 towards the southeast Atlantic Ocean, where there are few cirrus clouds. However, it does not impact the weighting of statistics elsewhere in the study, where the data are not limited to retrievals which can be collocated to a CALIOP overpass. A comparison of mean SEVIRI day- and night-time retrieval biases (Fig. B1) with a similar plot in Benas et al. (2016) (Fig. 6-15, row 3, column 3 ) indicates that this difference in methodology does not lead to a large difference in the spatial distribution of the mean retrieval biases.

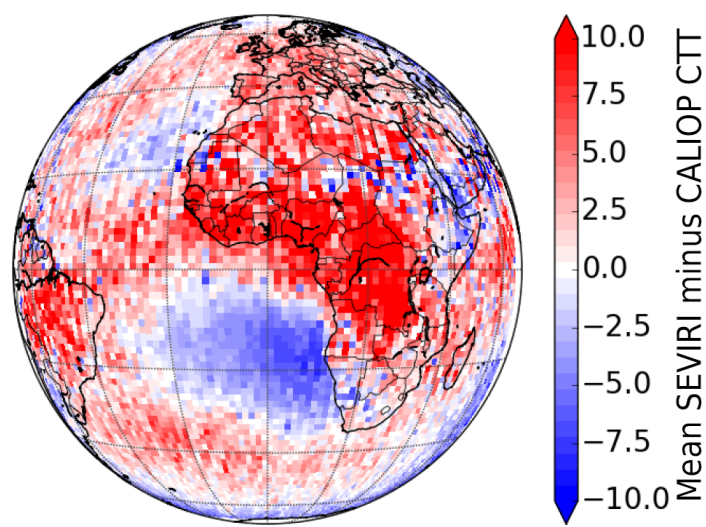

Figure B1. Spatial distribution of mean daytime (13:30 LST CALIOP overpass) and night-time (01:30 LST CALIOP overpass) bias in SEVIRI cloud top temperature retrievals during 2007. This plot is the same as the "Day and night" plot in Fig. 6 but plotted using the same scale as Figs. 6-15 in Benas et al. (2016) for ease of comparison. 
Author contributions. Sarah Taylor and Philip Stier co-designed the study. Sarah Taylor analysed the data and wrote the paper. Philip Stier and Bethan White provided suggestions for the methodology, discussed results, and commented on the manuscript at all stages. Stephan Finkensieper and Martin Stengel developed the CLAAS-2 dataset and provided advice on its use.

Competing interests. The authors declare that they have no conflict of interest.

Acknowledgements. SEVIRI CLAAS version 2 data were obtained from EUMETSAT's Climate Monitoring Satellite Applications Facility (CMSAF). CALIOP data were obtained from the NASA Langley Research Center Atmospheric Science Data Center. This work was supported with funding from the European Research Council under the European Union's Seventh Framework Programme (FP7 2007-2013) ERC grant agreement no. FP7-280025.

Edited by: J.-Y. C. Chiu

Reviewed by: two anonymous referees

\section{References}

Bain, C. L., Magnusdottir, G., Smyth, P., and Stern, H.: Diurnal cycle of the Intertropical Convergence Zone in the east Pacific, J. Geophys. Res., 115, D23116, https://doi.org/10.1029/2010JD014835, 2010.

Benas, N., Finkensieper, S., van Zadelhoff, G., Hanschmann, T., Stengel, M., and Meirink, J. F.: Validation Report SEVIRI cloud products Edition 2 (CLAAS-2), Tech. rep., EUMETSAT Satellite Application Facility on Climate Monitoring, 2016.

CALIPSO Science Team: CALIPSO/CALIOP Level 2, Lidar Cloud Layer Data, version 3.01 NASA Atmospheric Science Data Center (ASDC), https://doi.org/10.5067/CALIOP/CALIPSO/CAL_ LID_L2_05kmCLay-Prov-V3-01_L2-003.01, 2015.

Chen, S. S. and Houze, R. A.: Diurnal variation and life-cycle of deep convective systems over the tropical Pacific warm pool, Q. J. Roy. Meteor. Soc., 123, 357-388, 1997.

Dai, A.: Global Precipitation and Thunderstorm Frequencies. Part II : Diurnal Variations, J. Climate, 14, 1112-1128, 2001.

Dee, D. P., Uppala, S. M., Simmons, A. J., Berrisford, P., Poli, P., Kobayashi, S., Andrae, U., Balmaseda, M. A., Balsamo, G., Bauer, P., Bechtold, P., Beljaars, A. C. M., van de Berg, L., Bidlot, J., Bormann, N., Delsol, C., Dragani, R., Fuentes, M., Geer, A. J., Haimberger, L., Healy, S. B., Hersbach, H., Hólm, E. V., Isaksen, L., Kållberg, P., Köhler, M., Matricardi, M., McNally, A. P., Monge-Sanz, B. M., Morcrette, J.-J., Park, B.-K., Peubey, C., de Rosnay, P., Tavolato, C., Thépaut, J.-N., and Vitart, F.: The ERA-Interim reanalysis: configuration and performance of the data assimilation system, Q. J. Roy. Meteor. Soc., 137, 553-597, https://doi.org/10.1002/qj.828, 2011.

Derrien, M.: Algorithm Theoretical Basis Document for "Cloud Products" (CMa-PGE01 v3.2, CT-PGE02 v2.2 and CTTHPGE03 v2.2), SAF/NWC/CDOP2/MFL/SCI/ATBD/01, Issue 3, Rev. 2.1, Tech. rep., EUMETSAT Satellite Application Facility on Nowcasting and Shortrange Forecasting, 2013.
Duynkerke, P. G., de Roode, S. R., van Zanten, M. C., Calvo, J., Cuxart, J., Cheinet, S., Chlond, A., Grenier, H., Jonker, P. J., Köhler, M., Lenderink, G., Lewellen, D., Lappen, C.-L., Lock, A. P., Moeng, C.-H., Müller, F., Olmeda, D., Piriou, J.-M., Sánchez, E., and Sednev, I.: Observations and numerical simulations of the diurnal cycle of the EUROCS stratocumulus case, Q. J. Roy. Meteor. Soc., 130, 3269-3296, 2004.

Finkensieper, S., Meirink, J.-F., van Zadelhoff, G.-J., Hanschmann, T., Benas, N., Stengel, M., Fuchs, P., Hollmann, R., and Werscheck, M.: CLAAS-2: CM SAF CLoud property dAtAset using SEVIRI - Edition 2, Satellite Application Facility on Climate Monitoring, https://doi.org/10.5676/EUM_SAF_CM/CLAAS/V002, 2016.

Grabowski, W. W., Bechtold, P., Cheng, A., Forbes, R., Halliwell, C., Khairoutdinov, M., Lang, S., Nasuno, T., Petch, J., Tao, W.K., Wong, R., Wu, X., and Xu, K.-M.: Daytime convective development over land: A model intercomparison based on LBA observations, Q. J. Roy. Meteor. Soc., 132, 317-344, 2006.

Gray, W. M. and Jacobsen, R. W.: Diurnal variation of deep cumulus convection, Mon. Weather Rev., 105, 1171-1188, 1977.

Guichard, F., Petch, J., Redelsperger, J.-L., Bechtold, P., Chaboureau, J.-P., Cheinet, S., Grabowski, W., Grenier, H., Jones, C., Köhler, M., Piriou, J.-M., Tailleux, R., and Tomasini, M.: Modelling the diurnal cycle of deep precipitating convection over land with cloud-resolving models and single-column models, Q. J. Roy. Meteor. Soc., 130, 3139-3172, 2004.

Halladay, K., Malhi, Y., and New, M.: Cloud frequency climatology at the Andes/Amazon transition: 1. Seasonal and diurnal cycles, J. Geophys. Res., 117, D23102, https://doi.org/10.1029/2012JD017770, 2012.

Hamann, U., Walther, A., Baum, B., Bennartz, R., Bugliaro, L., Derrien, M., Francis, P. N., Heidinger, A., Joro, S., Kniffka, A., Le Gléau, H., Lockhoff, M., Lutz, H.-J., Meirink, J. F., Minnis, P., Palikonda, R., Roebeling, R., Thoss, A., Platnick, S., Watts, P., and Wind, G.: Remote sensing of cloud top pressure/height from SEVIRI: analysis of ten current retrieval algorithms, Atmos. Meas. Tech., 7, 2839-2867, https://doi.org/10.5194/amt-72839-2014, 2014.

Harrison, E. F., Brooks, D. R., Minnis, P., Wielicki, B. A., Staylor, W. F., Gibson, G. G., Young, D. F., and Frederick M. Den: First estimates of the diurnal variation of longwave radiation from the multiple-satellite Earth radiation budget experiment (ERBE), B. Am. Meteorol. Soc., 69, 1144-1151, 1988.

Harrison, E. F., Minnis, P., Barkstrom, B. R., Ramanathan, V., Cess, R. D., and Gibson, G. G.: Seasonal Variation of Cloud Radiative Forcing Derived From the Earth Radiation Budget Experiment, J. Geophys. Res., 95703, 687-18, 1990.

Heidinger, A. K. and Pavolonis, M. J.: Gazing at Cirrus Clouds for 25 Years through a Split Window. Part I: Methodology, J. Appl. Meteorol. Clim., 48, 1100-1116, 2009.

Heymsfield, G. M., Spinhirne, J. D., and Fulton, R.: Aircraft overflight measurements of midwest severe storms - Implications on geosynchronous satellite interpretations, Mon Weather Rev., 119, 436-456, https://doi.org/10.1175/15200493(1991)119<0436:AOMOMS>2.0.CO;2, 1991.

Higgins, G., Kassam, A., Kowal, J., Sarraf, S., Arnoldussen, H., Frere, M., Hrabovszki, J., and van Velthuizen, H.: Report on the Agro-ecological zones project, Vol. 1 Methodology and results for Africa. World soil resources report No 48, Tech. rep., AGLS, 
Food and Agriculture Organization of the United Nations, Rome, Italy, 1978.

Janowiak, J. E., Arkin, P. A., and Morrissey, M.: An examination of the diurnal cycle in oceanic tropical rainfall using satellite and in situ data, Mon. Weather Rev., 122, 2296-2311, 1994.

Kniffka, A., Lockhoff, M., Stengel, M., and Meirink, J. F.: Validation Report - SEVIRI cloud products, SAF/CM/DWD/VAL/SEV/CLD Issue 1, Rev. 1.2, Tech. rep., EUMETSAT Satellite Application Facility on Climate Monitoring, 2013.

McGill, M. J., Vaughan, M. A., Trepte, C. R., Hart, W. D., Hlavka, D. L., Winker, D. M., and Kuehn, R.: Airborne validation of spatial properties measured by the CALIPSO lidar, J. Geophys. Res., 112, D20201, https://doi.org/10.1029/2007JD008768, 2007.

Meirink, J. F.: Algorithm Theoretical Basis Document, Cloud Physical Products, SEVIRI. V 1.2, Tech. rep., EUMETSAT Satellite Application Facility on Climate Monitoring, SAF/CM/KNMI/ATBD/SEV/CPP, 2013.

Meisner, B. N. and Arkin, P. A.: Spatial and annual variations in the diurnal cycle of large-sacle tropical convective cloudiness and precipitation, Mon. Weather Rev., 115, 2009-2032, 1987.

Menzel, W. P., Stewart, T. R., and Smith, W. L.: Improved cloud motion wind vector and altitude assignment using VAS, J. Clim. Appl. Meteorol., 22, 377-384, 1983.

Minnis, P., Yost, C. R., Sun-Mack, S., and Chen, Y.: Estimating the top altitude of optically thick ice clouds from thermal infrared satellite observations using CALIPSO data, Geophys. Res. Lett., 35, 1-6, 2008.

NASA: CALIPSO Quality Statements Lidar Level 2 Cloud and Aerosol Layer Products Version Releases: 3.01, 3.02, Tech. rep., NASA, 2011.

NASA: CALIPSO: Data User's Guide - Data Product Descriptions - Lidar Level 2 Cloud and Aerosol Layer Products, available at: http://www-calipso.larc.nasa.gov/resources/ calipso_users_guide/data_summaries/layer/index.php (last access: 3 November 2016), 2013.

NASA: GEOS-5 FP-IT Product Details, available at: https://gmao.gsfc.nasa.gov/products/GEOS-5_FP-IT_details. php\#output_product_highlights (last access: 3 November 2016), 2017.

Nesbitt, S. W. and Zipser, E. J.: The Diurnal Cycle of Rainfall and Convective Intensity according to Three Years of TRMM Measurements, J. Climate, 16, 1456-1475, 2003.

Pearson, K. J., Hogan, R. J., Allan, R. P., Lister, G. M. S., and Holloway, C. E.: Evaluation of the model representation of the evolution of convective systems using satellite observations of outgoing longwave radiation, J. Geophys. Res.-Atmos., 115, 1-11, https://doi.org/10.1029/2010JD014265, 2010.

Pearson, K. J., Lister, G. M. S., Birch, C. E., Allan, R. P., Hogan, R. J., and Woolnough, S. J.: Modelling the diurnal cycle of tropical convection across the "grey zone", Q. J. Roy. Meteor. Soc., 140, 491-499, https://doi.org/10.1002/qj.2145, 2014.

Pfeifroth, U., Trentmann, J., Fink, A. H., and Ahrens, B.: Evaluating satellite-based diurnal cycles of precipitation in the African tropics, J. Appl. Meteorol. Climatol., 55, 23-39, 2016.

Randall, D. A., Harshvardhan, and Dazlich, D. A.: Diurnal Variability of the Hydrologic Cycle in a General Circulation Model, J. Atmos. Sci. 48, 40-62, 1991.
Reuter, M., Thomas, W., Albert, P., Lockhoff, M., Weber, R., Karlsson, K.-G., and Fischer, J.: The CM-SAF and FUB Cloud Detection Schemes for SEVIRI: Validation with Synoptic Data and Initial Comparison with MODIS and CALIPSO, J. Appl. Meteorol. Clim., 48, 301-316, 2009.

Rickenbach, T., Ferreira, R. N., Guy, N., and Williams, E.: Radarobserved squall line propagation and the diurnal cycle of convection in Niamey, Niger, during the 2006 African monsoon and multidisciplinary analyses intensive observing period, J. Geophys. Res.-Atmos., 114, 1-8, 2009.

Rienecker, M. M., Suarez, M. J., Todling, R., Bacmeister, J., Takacs, L., Liu, H.-C., Gu, W., Sienkiewicz, M., Koster, R. D., R., G., Stajner, I., and Nielsen, J. E.: The GEOS-5 Data Assimilation System - Documentation of Versions 5.0.1 , 5.1.0, and 5.2.0, Tech. rep., NASA, 2008.

SAFNWC/MSG: Algorithm Theoretical Basis Document for "Cloud Products" (CMa-PGE01 v3.2, CT-PGE02 v2.2 and CTTH-PGE03 v2.2) SAF/NWC/CDOP/MFL/SCI/ ATBD/01, Issue 3, Rev. 2, Tech. rep., NWC SAF, 2012.

Sato, T., Miura, H., Satoh, M., Takayabu, Y. N., and Wang, Y.: Diurnal Cycle of Precipitation in the Tropics Simulated in a Global Cloud-Resolving Model, J. Climate, 22, 4809-4826, 2009.

Schmetz, J., Holmlund, K., Hoffman, J., Strauss, B., Mason, B., Gaertner, V., Koch, A., and Van De Berg, L.: Operational CloudMotion Winds from Meteosat Infrared Images, J. Appl. Meteorol., 32, 1206-1225, 1993.

Schröder, M., König, M., and Schmetz, J.: Deep convection observed by the Spinning Enhanced Visible and Infrared Imager on board Meteosat 8: Spatial distribution and temporal evolution over Africa in summer and winter 2006, J. Geophys. Res., 114, D05109, https://doi.org/10.1029/2008JD010653, 2009.

Sherwood, S. C., Chae, J. H., Minnis, P., and McGill, M.: Underestimation of deep convective cloud tops by thermal imagery, Geophys. Res. Lett., 31, 1-4, 2004.

Smith, W. L. and Platt, C. M. R.: Comparison of Satellite-Deduced Cloud Heights with Indications from Radiosonde and GroundBased Laser Measurements, J. Appl. Meteorol., 17, 1796-1802, 1978.

Stengel, M., Kniffka, A., Meirink, J. F., Lockhoff, M., Tan, J., and Hollmann, R.: CLAAS: the CM SAF cloud property data set using SEVIRI, Atmos. Chem. Phys., 14, 4297-4311, https://doi.org/10.5194/acp-14-4297-2014, 2014.

Stratton, R. A. and Stirling, A. J.: Improving the diurnal cycle of convection in GCMs, Q. J. Roy. Meteor. Soc., 138, 1121-1134, 2012.

Stubenrauch, C. J., Cros, S., Guignard, A., and Lamquin, N.: A 6-year global cloud climatology from the Atmospheric InfraRed Sounder AIRS and a statistical analysis in synergy with CALIPSO and CloudSat, Atmos. Chem. Phys., 10, 7197-7214, https://doi.org/10.5194/acp-10-7197-2010, 2010.

Stubenrauch, C. J., Rossow, W. B., Kinne, S., Ackerman, S., Cesana, G., Chepfer, H., Di Girolamo, L., Getzewich, B., Guignard, A., Heidinger, A., Maddux, B. C., Menzel, W. P., Minnis, P., Pearl, C., Platnick, S., Poulsen, C., Riedi, J., Sun-Mack, S., Walther, A., Winker, D., Zeng, S., and Zhao, G.: Assessment of global cloud datasets from satellites: Project and database initiated by the GEWEX radiation panel, B. Am. Meteorol. Soc., 94, 1031-1049, 2013. 
Vaughan, M. A., Winker, D. M., and Powell, K. A.: CALIOP Algorithm Theoretical Basis Document Part 2 : Feature Detection and Layer Properties Algorithms, Tech. Rep. September, NASA, 2005.

Vaughan, M. A., Powell, K. A., Winker, D. M., Hostetler, C. A., Kuehn, R. E., Hunt, W. H., Getzewich, B. J., Young, S. A., Liu, Z., and McGill, M. J.: Fully Automated Detection of Cloud and Aerosol Layers in the CALIPSO Lidar Measurements, J. Atmos. Ocean. Technol., 26, 2034-2050, 2009.

Vondou, D. A., Nzeukou, A., and Kamga, F. M.: Diurnal cycle of convective activity over the West of Central Africa based on Meteosat images, Int. J. Appl. Earth Obs., 12, 58-62, 2010.

Waliser, D. E. and Gautier, C.: A satellite-derived climatology of the ITCZ, J. Climate, 6, 2162-2174, 1993.

Wallace, J. M.: Diurnal variations in precipitation and thunderstorm frequency over the contermonous United States, Mon. Weather Rev., 103, 406-419, 1975.
Wild, M., Folini, D., Hakuba, M. Z., Schar, C., Seneviratne, S. I., Kato, S., Rutan, D., Ammann, C., Wood, E. F., and KonigLanglo, G.: The energy balance over land and oceans: an assessment based on direct observations and CMIP5 climate models, Clim. Dynam., 44, 3393-3429, 2014.

Winker, D. M., Hostetler, C. A., Vaughan, M. A., and Omar, A. H.: CALIOP algorithm theoretical basis document. Part 1: CALIOP instrument, and algorithms overview, Tech. rep., NASA, 2006.

Wood, R.: Diurnal cycle of liquid water path over the subtropical and tropical oceans, Geophys. Res. Lett., 29, 2092, https://doi.org/10.1029/2002GL015371, 2002.

Yang, G.-Y. and Slingo, J.: The Diurnal Cycle in the Tropics, Mon. Weather Rev., 129, 784-801, 2001.

Yang, S., Kuo, K.-S., and Smith, E. A.: Persistent Nature of Secondary Diurnal Modes of Precipitation over Oceanic and Continental Regimes, J. Climate, 21, 4115-4131, 2008. 